\title{
Systemic Complications of Complex Regional Pain Syndrome
}

\author{
Robert J. Schwartzman \\ Department of Neurology, Drexel University College of Medicine, Philadelphia, USA. \\ Email: Robert.schwartzman@drexelmed.edu
}

Received July $18^{\text {th }}, 2012$; revised August $15^{\text {th }}, 2012$; accepted August $22^{\text {nd }}, 2012$

\begin{abstract}
Complex Regional Pain Syndrome (CRPS) is a neuropathic pain disorder that is characterized by: 1) Severe pain beyond the area of injury; 2) Autonomic dysregulation; 3) Neuropathic edema; 4) A movement disorder, atrophy and dystrophy. It is most often caused by a fracture, soft-tissue injury or surgical procedure and is divided into Type I, in which no nerve lesion is identified (classic reflex sympathetic dystrophy), and Type II where a specific nerve has been damaged (causalgia). In addition to the peripheral manifestations, there are many internal medical complications whose etiology is often not appreciated. This article will examine how CRPS affects the systems of: cognition; constitutional, cardiac, and respiratory complications; systemic autonomic dysregulation; neurogenic edema; musculoskeletal, endocrine and dermatological manifestations; as well as urological and gastrointestinal function.
\end{abstract}

Keywords: Complex Regional Pain Syndrome; CRPS; CRPS-1; CRPS-2; Chronic Pain; Reflex Sympathetic Dystrophy; RSD

\section{Introduction}

Complex Regional Pain Syndrome (CRPS) is a neuropathic pain disorder that is characterized by: 1) Severe pain beyond the area of injury; 2) Autonomic dysregulation; 3) Neuropathic edema; 4) A movement disorder, atrophy and dystrophy [1]. It is most often caused by a fracture, soft-tissue injury or surgical procedure and is divided into Type I, in which no nerve lesion is identified (classic reflex sympathetic dystrophy), and Type II where a specific nerve has been damaged (causalgia). Converging evidence suggests that CRPS-I is due to injury and distal degeneration of axons and terminal twigs of A- $\delta$ and C fibers [2]. Cluster analysis reveals that the signs and symptoms in the syndrome comprise four distinct groups: 1) Abnormalities in pain processing (mechanical and thermal allodynia; hyperalgesia, and hyperpathia); 2) Temperature change and erythema, cyanosis or mottling; 3) Neurogenic edema and sudomotor dysregulation; 4) A motor syndrome and trophic changes [3-7]. There may be subtypes: 1) A limited syndrome with predominant autonomic dysregulation; 2) A syndrome limited to one extremity that is characterized by neuropathic pain with minimal autonomic dysregulation and neurogenic edema; 3) A severe disorder that has spread from the site or original injury, is long standing and comprises all components of the syndrome [4]. The present diagnostic criterion requires at least one symptom in each of the four factors and one sign in at least two of the four factors [7]. In general, early in the course of the disease patients demonstrate prominent inflammatory signs and symptoms that include neurogenic edema, erythema and an increased temperature of the affected extremity while long standing patients suffer pain spread and an apparent centralization of the process with concomitant severe generalized autonomic motor and trophic changes of skin, nails, bone and muscle [1,8-11].

The epidemiology of the syndrome is uncertain. Many patients diagnosed with fibromyalgia clearly have CRPS, the pressure points being components of the brachial plexus, the intercostobrachial (ICB) nerve and concomitant $\mathrm{L}_{5}-\mathrm{S}_{1}$, injury $[12,13]$. The most representative population-based study from the Netherlands revealed an incidence of 40.4 females and 11.9 males per 100,000 person-years at risk [14]. The variable incidence reported are due to the cohorts studied, the time period in the course of the disease in which they were studied and the skill of the examiners [15-19].

The purpose of this article is to discuss the systemic medical complications of CRPS. As Janig has pointed out, with time CRPS centralizes to affect somatosensory, autonomic and limbic components of the syndrome [20]. The immune component of neuropathic pain is now viewed as pivotal to both in its initiation and maintenance. Many of the features seen peripherally occur in 
systemic organs.

\section{Neuropsychological Deficits Associated with CRPS}

Severe neuropathic chronic pain is associated with poor performance on neuropsychological tests that assess working memory, language and executive function [21-23]. Patients whose pain was due to a variety of underlying medical conditions demonstrated decreased information processing speed [24].

Over 500 patients with severe CRPS (met all IASP criteria [25]) underwent a battery of neuropsychological tests that assesses executive systems function, naming/ lexical retrieval, memory and learning prior to treatment with an outpatient ketamine protocol. The assessment method is based on the work of Libon et al. [26]. Executive system function was measured by the digit span subtest from the Wechsler Adult Intelligence Scale-III (WAIS-III) [27]. The digits backward portion of the test was used to evaluate working memory deficits $[28,29]$. Executive function was also evaluated by tests of letter fluency which activate the left dorsolateral prefrontal cortex in both young and older patients [30]. Naming was assessed with the Boston Naming Test [31] and lexical retrieval by a test of semantic fluency [32]. Converging evidence supports category fluency tests as a measure of lexical retrieval and semantic knowledge that activate the left temporal lobe $[33,34]$. Memory and learning was evaluated by the California Verbal Learning Test-II [35]. Delayed free recall and delayed recognition discrimination index have been linked to parahippocampal atrophy and the presence of anterograde amnesia [29]. Adjunctive tests administered with the above were the McGill Pain Inventory [36] and the Beck Depression Inventory-II [37]. The patterns of neuropsychological impairment seen in this large cohort of CRPS patients were determined by a statistical cluster algorithm which demonstrated three distinct groups. Approximately 35\% of patients had no neuropsychological deficits, group I. The second, group II, $42 \%$ of patients had mild dysexecutive deficits. Group III, 22\% of patients had cognitive impairment that included poor performance on tests of executive function, naming and memory. Both affected CRPS groups II and III (65\%) of patients) had difficulty with repeating numbers backward. This function is thought to demonstrate higher-order mental manipulation that depends on working memory and visual imagery mechanisms [26]. There is also evidence that decreased output on letter fluency and poor performance on a backwards digit span test are correlated with left inferior frontal lobe pathology [34]. CRPS group III patients' memory deficits suggest executive (retrieval) rather than amnesic (encoding) dysfunction. The improvement of this group in the delayed recognition test suggests impairment of frontal memory systems [38]. This detailed evaluation of over 500 patients suggests that a wide network of cortical and subcortical anatomical nodes is involved in the illness and that a dysexecutive syndrome is the primary deficit. A neurocognitive study on nine patients prior to and following a ketamine anesthesia protocol [39] by Koffler demonstrated improvement in brief auditory attention and processing speed [40]. Levels of depression and extent (number of limbs involved) or duration of illness is not a factor in these cognitive changes.

Functional MRI (fMRI) studies in patients with CRPSI and II have given insights into cognitive function and activity dependent neuroplasticity in this illness. There is clear alteration of the CRPS hand representation in the primary somatosensory cortex (SI) cortex of the affected versus unaffected side [41-44]. The side opposite the affected hand is decreased or increased [44] in parallel with the degree of mechanical hyperalgesia and pain intensity $[41,42]$ which reversed with recovery $[42,43]$. In a recent study, patients with CRPS estimated their hand size of the affected extremity to be larger when compared to expanded or compressed schematic drawings of hands. The overestimation correlated with disease duration, increased two-point discrimination and neglect score [44]. In addition to tactile and proprioceptive deficits [45], a significant proportion of CRPS patients feel as if their hand is "foreign or strange" [46] or not belonging to their body [47]. Studies with fMRI during electrical stimulation of both index fingers revealed smaller signals in both contralateral SI and secondary somatosensory cortices (SII) that were associated with impaired 2-point discrimination deficits. This suggests that patterns of cortical reorganization in both SI and SII parallel impaired tactile discrimination [48] and pain intensity. In addition to plastic aberrations of the body schema in CRPS patients, increased activation of areas thought to process affective components of pain, the cingulate gyrus and frontal cortices have been demonstrated that may persist after recovery [41,49]. A recent paper describes the neuropsychological dissociation in which a CRPS patient had preservation of object recognition and naming but was unable to recognize object orientation (agnosia for object orientation) [50]. This finding may be consistent with a previous fMRI study that demonstrated aberrant activation within the intraparietal sulcus (a multimodal association area) and was associated with motor dysfunction [51]. The impaired spatial orientation demonstrated by this patient suggests posterior parietal dysfunction.

The impaired cognitive function demonstrated by these studies may also be associated with structural brain changes demonstrated in other severe neuropathic pain states and in CRPS patients maybe at least partially reversible $[40,52]$. Factors that also have to be considered 
in the cognitive performance of patients with severe neuropathic CRPS pain are medication, stress, and distraction that detract from working memory [53,54]. A recent experimental study on resolving postoperative neuroinflammation and cognitive decline suggests a mechanism for the neuropsychological deficits defined in CRPS patients [55]. In C57BL/6J and other species of mice, peripheral surgery was shown to cause disruption of the blood brain barrier (BBB). The proposed mechanism was release of tumor necrosis factor-alpha (TNF- $\alpha$ ) that facilitated the migration of macrophages into the hippocampus by activation of nuclear factor kappa B (NF- $\kappa \mathrm{B})$. This signaling pathway induces neuroinflammation, microglial activation and release of proinflammatory cytokines. Activation of the alpha7 nAChR (acetylcholine receptor) prevented the migration of monocyte-derived macrophages into the CNS. Entry of leukocyte like CD4 + T cells may be mediated by NF- $\kappa$ B amplification of interleukin-6 (IL-6) that is expressed in cerebral endothelial cells and can lead to increased expression and accumulation of inflammatory cytokines. This endothelial activation and breakdown of the BBB may be initiated by peripheral nerve injury [56].

\section{Constitutional Symptoms}

CRPS-I and CRPS-II are systematic diseases which can potentially affect any organ system [1,15]. Almost all severely affected patients (those with more that one extremity involved) have complaints of lethargy, tiredness, or weakness-the etiology of which is multifactorial. Following injury mast cells, macrophages, leukocytes are activated and recruited to the involved area [57]. As the illness progresses proinflammatory cytokines increase in the serum and cerebrospinal fluid (TNF- $\alpha$ and IL-6) while anti-inflammatory cytokines Interleukin-4 (IL-4) and Interleukin-10 (IL-10) decline [57-65]. Inflammatory cytokines act both peripherally at the site of injury and in the CNS at multiple levels in the pain matrix [57]. In patients with long-standing disease the percentage of CD14+ and CD16+ monocyte/macrophage activity (proinflammatory) in the serum increases although the total monocyte count remains normal [66] and anti-inflammatory cytokines such as IL-10 decreases. Further evidence for autoimmune mechanisms in the pathophysiology of the constitutional symptoms noted in CRPS is suggested by the finding that approximately $35 \%$ of patients have surface-binding autoantibodies against sympathetic and mesenteric plexus neurons $[67,68]$.

The body's initial nonspecific immune activation following injury or infection is evident within hours and is called the sickness response. It is initiated by immune system to brain interactions that trigger a cascade of nervous system reactions that include pain facilitation [69].
As noted above, inflammatory cytokines are released from activated immune cells at the site of injury. Interleukin-1 (IL-1), IL-6 and TNF- $\alpha$ activate specialized sensory structures, paraganglia, that synapse with sensory vagal fibers [70-72]. Sickness-induced pain facilitation can be blocked in experimental neuropathic pain models by IL- 1 receptor antagonists, TNF- $\alpha$ binding protein or subdiaphragmatic vagotomy [73-77]. The severe fatigue suffered by CRPS patients may result in part from the sickness response circuitry [76]. Other contributing comorbidities are disruptions of sleep architecture, hypothyroidism, secondary hypoadrenalism from a chronic stress response, deconditioning and severe depresssion.

\section{Cardiac Complications of CRPS}

Approximately 2500 CRPS patients with disease duration of greater than 2 years and at least two-extremity involvement have been evaluated at the Drexel University Pain Clinic. Five hundred had EKG and echocardiogram evaluation prior to sub-anesthetic ketamine treatment. There were no specific EKG abnormalities other than a higher than normal pulse rate ranging from 80 100 beats per minute. The ejection fraction was between $50 \%$ - 65\% which did not differ from control male and female controls. Approximately $10 \%$ of patients described syncope or presyncope during the course of their illness [78]. Seventy four patients underwent head-up tilt test (HUTT) to evaluate their complaints of syncope and were compared to an age and gender-matched comparator group and to literature standards of control patients that underwent HUTT. The mean duration of CRPS of the tested patients was 6.5 years whose average pain on a Likert numeric scoring system was 7.7 ( 0 being no pain and 10 being the worst pain imaginable). All patients were extremely ill and had some spread of pain from the original site of injury. Twenty nine patients (39\%) had generalized total body CRPS. Eight patients were not able to complete a HUTT due to pain. Twenty eight (42.4\%) CRPS patients out of the sixty six tested had a positive HUTT that could be classified as: 1) 17 (61\%) mixed response (heart rate decreased by greater that $10 \%$ but does not decrease to less than 40 beats per minute for greater than 10 seconds and the blood pressure fell prior to heart rate; 2) 1 patient (4\%) had cardioinhibition without asystole in which blood pressure falls before heart rate; 3) Two patients (7.1\%) had a cardioinhibitory response with asystole in which the blood pressure fell prior to a decreased heart rate. Three patients (11\%) demonstrated a vasodepressor response in which the heart rate does not fall greater than 10\% from the maximum rate during tilt. The fall in blood pressure however precipitates syncope [79]. The majority of CRPS patients (23/28; 88\%) required nitroglycerine provocation to in- 
duce a positive HUTT. There was no correlation between specific pain characteristics (dynamic or static mechanical allodynia, hyperalgesia or hyperpathia) or duration of illness with positive a head-up tilt test although it occurred more frequently in younger patients. CRPS patients were 4.5 times more likely to have a positive HUTT than age and gender-matched control subjects. There was no significant difference in heart rate variability between CRPS patients with or without a positive HUTT. Fifty four percent of our HUTT-positive CRPS patients were less than 40 years of age. Approximately $38 \%$ of the CRPS patients that completed the study had at least one prior complaint of presyncope or syncope. CRPS patients with involvement of the lower limbs are more likely to have vasovagal syncope and positive orthostatic HUTT than those with upper extremity or total body disease. Patients with CRPS have an enhanced predisposition to neurocardiogenic syncope during head-up tilt table testing compared to the vasovagal response of historical controls of asymptomatic subjects [80-83]. In children and adolescents with CRPS the tilt test demonstrates orthostatic stability but a higher mean heart rate with tilt than in control subjects [84]. Another recent study of twenty age, sex and body-mass index-matched control subjects demonstrated increased heart rate and decreased heart rate variability in CRPS patients during rest, mental and orthostatic stress. Baroreceptor sensitivity was maintained [85]. During a 60 degree tilt, CRPS patients had a drop in cardiac output and an exaggerated increase in total peripheral resistance. The autonomic changes correlated with disease duration but not pain intensity. The authors concluded that the increased heart rate and decreased heart rate variability was due to a generalized autonomic imbalance and increased their susceptibility to sudden death [85]. Evidence is emerging that measures of reduced heart rate variability may be a prognostic factor for cardiac arrhythmias [86].

Atypical chest pain is a common complaint of patients with CRPS. Most of these patients have suffered a neuropathic ICB nerve traction injury [13]. Atypical chest pain often presents in young women who uncommonly have coronary artery disease (CAD). If CAD is present, they have a $7 \%$ higher risk of death than age matched men [87]. Noninvasive cardiac screening tests that include stress EKG are less sensitive in female patients [88]. This often leads to coronary arteriography in these patients where the ICB nerve is generating the chest pain.

Approximately $25 \%$ of all coronary angiograms are negative in the general population and no positive studies have been seen in our young patients with sensitized ICB nerves from trauma or CRPS [89]. Most of our patients with chest pain complained of anterior lateral and under the breast pain and received extensive cardiac evaluations that ended with negative catheter studies. The pa- tients themselves did not think that their chest pain was related to their CRPS. The majority of chest pain reported by these patients ( $\mathrm{n}=35$ in the Rasmussen study) [13] was bilateral (66\%), radiated to the jaw/head/neck (concomitant cervical plexus C2-C4 involvement) [90] and the brachial plexus distributions in the shoulder and arm (46\%). The majority of these patients that sought care from their primary care physicians received an EKG (79\%) or were diagnosed with chest pain of unknown origin (26\%); costochondritis (21\%); psychosomatic illness (21\%); cardiac disease (16\%); Gastroesophageal reflux disease (GERD) (5\%); hormonal disorders (11\%) and diseases of unknown etiology (26\%).

In the CRPS patients, only $40 \%$ described their pain or burning while most (60\%) felt it as deep or aching. Approximately $65 \%$ of CRPS patients could elicit the chest pain by elevating their arm and stretching the brachial plexus that in turn would cause traction on the ICB nerve. It has been demonstrated experimentally that nerve injury over time induces pain markers on somatic mechanical afferent nerves which then activate dorsal horn pain transmission neurons [91]. The anatomy of the nerve explains its radiations and how discharge in its territory can easily be confused with coronary artery pain. It arises from the second intercostal nerve (T2) with variable contributions from T3 and T4 nerve roots [92,93]. The ICB nerve innervates the axilla, medial and anterior arm as well as contributing to the innervation with the posterior antebrachial cutaneous nerve. It innervates the anterior chest wall by connections to the long thoracic nerve [92, 93] and on occasion innervates the pectoralis minor and major muscles [93]. In thirty percent of patients the ICB nerve is connected to the brachial plexus from the medial cord [94]. T2 is the primary root of the ICB nerve and connects to the brachial plexus $100 \%$ of the time, either via the ICB nerve (80\%) or from direct intrathoracic connections in $20 \%$ of patients [95]. The nerve is very frequently injured during breast surgery [96-98] which may also cause CRPS.

\section{Respiratory System}

In the longitudinal study of 270 consecutive patients with moderate to severe CRPS, shortness of breath was reported in 42 (15.5\%) [1]. Evaluation of these patients revealed subsegmental atelectasis on chest x-ray in 33\%, low lung volume in $16.7 \%$ and only one patient $(0.5 \%)$ had evidence of chronic obstructive lung disease (COPD). One patient had mild congestive heart failure. Hilar adenopathy and small pleural effusions were noted in three patients. Nine of the 42 patients underwent formal pulmonary function tests. Five had restrictive lung disease and two had mild restrictive lung disease. One patient had normal studies. 
In addition to these non-specific pulmonary abnormalities, many patients complain of not being able to take a deep breath. Dystonia of the chest wall muscles is common in severe long-standing patients but no epidemiological studies have been done that would determine its incidence and prevalence. Dystonia is a major component of the movement disorder of CRPS [99-102]. That it can affect chest wall muscles causing restrictive lung disease has only recently been recognized [103]. In general, the presence of dystonia in CRPS patients is associated with a younger age and longer duration of disease [101]. The onset of dystonia is variable but may precede other manifestations of the disease [99]. Another cause of chest wall discomfort that prevents patients from normal inspiration is irritation of the ICB nerve that often innervates pectoral and intercostal muscles [13]. Involvement of this nerve is most often confused with cardiac pain if it occurs on the left side and gall bladder disease if it is in the right chest wall.

\section{Systemic Manifestations of Autonomic Dysregulation in CRPS}

Failure of a compensatory reflex-induced increase in heart rate when blood pressure falls is a manifestation of autonomic dysregulation which has both peripheral and CNS components [20]. The affected extremities of CRPS patients are most often warm early in the course of the illness and then become cold which suggests a change in activity of the vasoconstrictor neurons in the spinal inter mediolateral column [104]. Clinical studies utilizing whole body warming and cooling combined with respiratory stimuli were utilized to evaluated CRPS patients who suffered various durations of the illness [105,106]. Those patients with less than four months of disease had a warm extremity and higher skin perfusion values than the unaffected extremity. Norepinepherine concentration from the affected extremity was decreased [106]. In those patients with mean disease duration of 15 months had either a warmer or cooler affected extremity that depended on variable sympathetic activity. Patients with cold affected extremities had disease duration of a mean of 28 months and also demonstrated low norepinephrine concentrations in the venous effluent from the affected extremity [106]. In a significant portion of long standing patients sympathetic vasoconstriction returns to normal although the affected extremity is cold [106]. It has been postulated that early in the illness there is central nervous system efferent autonomic dysregulation while over time there may be increased density or sensitivity of blood vessel noradrenergic receptors to circulating norepinephrine from the adrenal gland [107-110]. Earlier studies utilizing laser Doppler fluxemetery found that the normal reduction of skin blood flow from activation of the sym- pathetic efferents by a Valsalva maneuver or cold presser test was absent in CRPS patients. Sympathetic innervation of arterioles is the major innervation that controls blood flow to capillaries in the extremities. Vasomotion, the normal sympathetically mediated spontaneous wavelike fluctuations in veins are also reduced or absent in CRPS patients [110]. These earlier studies are supported by another study that demonstrated sympathetically induced vasoconstriction is reduced in early CRPS patients which returns to normal over time [106,111,112]. That sympathetic dysfunction maybe an early component of any post-traumatic neuropathy was suggested by a thermographic study of 200 injuries suffered by 1000 recruits during basic training [113]. Immobilization of an injured limb may also induce temperature changes in an injured extremity and maybe a risk factor for the subsequent development of CRPS [114,115]. Sudomotor dysfunction is common in CRPS patients both early and late in the course of illness. It usually manifests as an increased resting sweat output of the affected extremity [116]. Sweat glands normally respond to cholinergic stimulation but an adrenergic sweat response may occur in CRPS-affected limbs following iontophoresis of an alphaadrenergic agonist [117]. This suggests that in CRPS there is activation of systems that are not normally under adrenergic control.

Anatomical connections of the sympathetic nervous system innervation to afferent nociceptors occur after experimental axotomy $[118,119]$. In the dorsal root ganglion (DRG) sympathetic fibers from blood vessels sprout and form baskets around mechanoreceptors and innervate thinly myelinated fibers. This is in response to upregulation of p75 receptors that guide sympathetic fibers and lymphocyte inhibitory factor (LIF) that induces sympathetic nerve sprouting. There are other potential mechanisms for the coupling of sympathetic efferents to nociceptive afferents that occur at the site of injury [119]. Mechanosensitive sensory afferents and nociceptive fibers express adrenoreceptors that may be upregulated and activated following nerve injury. An increased density of $\alpha-1$ adrenergic receptors occurs in the hyperalgesic skin of CRPS-I patients $[119,120]$. The involvement of the sympathetic nervous system in CRPS is further demonstrated by: 1) The response of early CRPS patients to sympatholysis; 2) The demonstration of acute antibodies to sympathetic ganglia; 3) Denervation hypersensitivity of vascular smooth muscle (due to loss or dysfunction of vasomotor neurons in the intermediolateral column); 4) Sensitization of mechanoreceptors from the adrenal release of epinephrine; 5) Immune sympathetic system interaction [67,121-123].

The autonomic manifestations of CPRS are frequently misdiagnosed as Raynaud's phenomena (particularly if the affected extremity is minimally painful), fibromyal- 
gia and vascular insufficiency. This occurs in the setting of a cold blue extremity, with mottling and livedo reticularis and neurogenic edema. The erythematous warm extremity is often thought to be infected.

\section{Inflammation/Neurogenic Edema}

In a longitudinal study of over 600 patients with CRPS of at least one year's duration, 75\% were positive for neurogenic edema. In those with long standing disease, 90\% were positive. The swelling correlated with disease duration and may be generalized and massive [1]. There is often sustained diuresis at the initiation of ketamine therapy. The average weight loss of moderate to severely affected CRPS patients when the edema is mobilized is between 10 and 12 pounds. Diuretics are often administered for the edema and are ineffective. Frequently affected body parts are concomitantly erythematous as well as swollen. If these signs are present in a painful lower extremity, patients are misdiagnosed as suffering from thrombophlebitis. There are often severe dystrophic skin, nail and integument changes in the affected lower extremities that in association with erythema and increased temperature suggest infection.

At the site of injury an "inflammatory soup" develops. It originates from the blood or inflammatory cells that include: inflammatory cytokines (IL-1, IL-6 and TNF- $\alpha$, prostaglandins (PGE2), serotonin (5-hydroxy-tryptamine), bradykinin, epinephrine, lipoxygenase, neurotrophic factors (nerve growth factor (NGF), brain derived neurotrophic factor (BDNF)), neurotrophin-3 (NT-3) and nucleotide transmitters such as adenosine [124,125]. This microenvironment blurs the distinction between inflammatory or purely neuropathic pain in CRPS. The effect of these cytokines, neutrophilic factors, small molecules and enzymes is to directly activate the terminal membranes of $\mathrm{C}$ and $\mathrm{A}-\delta$ nociceptors or to decrease their firing threshold. This effect is mediated by activation of phosphokinase A (PKA) and phosphokinase C (PKC) which phosphorylate tetrodotoxin (TTX) resistant sensory neurons and specific sodium channels [126]. In addition, cytokines TNF- $\alpha$, Interleukin- 1 beta (IL-1 $\beta$ ) and IL-6 release calcitonin gene related peptide into the skin. Retrogradely transported NGF has also been shown to regulate gene expression (new receptors and proteins) and biosynthesis in neonatal rat sensory neurons [127, 128]. The activation of these $\mathrm{C}$ and $\mathrm{A}-\delta$ terminal twigs induces an axon reflex that releases the vasoactive neuropeptides substance-P, calcitonin gene related peptide (CGRP) and neurokinin A which causes vasodilation and protein extravasation. The associated neurogenic inflammation causes erythema, increased temperature and edema [129]. The majority of the neurogenic inflammation, edema and augmented flare response in CRPS patients are caused by substance-P and CGRP [130-134].
Substance-P has also been demonstrated to stimulate skin keratinocytes to express cytokines in the affected extremities of CRPS patients [135,136]. Further evidence for the involvement of inflammatory cytokines in neuroinflammation and edema in the affected extremities of CRPS patients is: 1) Increased concentration of TNF- $\alpha$ and IL-6 in skin blister fluid from fracture sites in the CRPS affected limb [58,59]; 2) Serum concentrations of soluble TNF receptors and TNF- $\alpha$ receptors, IL-1 and interleukin-8 (IL-8) are elevated in early CRPS (mean of 3 months) while the anti-inflammatory cytokines IL-4, IL-10 and transforming growth factor beta-1 (TGF $\beta-1$ ) are decreased $[62,131]$. A contrary study found that blister fluid and serum cytokine concentrations were not linked to disease duration or clinical signs other than mechanical hyperalgesia [62,137,138]. An aberrant inflammatory response to tissue injury inducing erythema, warmth and neurogenic edema appears to be an important aspect of CRPS. In addition to pain relief, these inflammatory changes respond dramatically to N-MethylD-aspartate (NMDA) blockade by ketamine protocols [139]. The erythema and neurogenic edema seen on both early and long standing CRPS patients is often mistaken for thrombophlebitis or infection when it occurs in the lower extremities. Unfortunately, the grossly edematous and poorly perfused lower extremities often do get infected.

\section{Musculoskeletal System}

The musculoskeletal system is profoundly affected in almost all patients with CRPS. Weakness was reported in approximately $70 \%$ of patients in a longitudinal study [1]. In addition to weakness, patients suffer atrophy in muscles that maybe normally exercised. This is apparent particularly in intrinsic hand and foot muscles as well as the gastrocnemius muscles. Occasionally a specific component of muscle will be atrophied in a muscle that does not appear to be involved with the illness. Evaluation of muscle from the amputated limbs of 14 severe end-stage CRPS patients revealed fatty degeneration, Type I and II fiber atrophy and evidence of degeneration with reinnervation. There was no difference in the pathology between arm or legs and no correlation with duration of illness [140]. Under hypoxic conditions elevated levels of reactive oxygen species are produced which act as second messengers that activate hypoxia inducible factors (HIPs) that help to maintain ATP levels [141]. Magnetic resonance spectroscopy has demonstrated that muscle in CRPS patients is hypoxic [142] which causes failure to maintain a normal redox state and that in turn will increase reactive oxygen species (ROS) production and cell injury [143]. Mitochondrial dysfunction has been demonstrated in severe late stage patients in limbs prior to amputation [144]. Biochemical analysis suggests that 
decreased activity of mitochondrial succinate dehydrogenase (complex II) is causative of mitochondrial energy production failure and free radical production [145]. ROS cause carbonylation of mitochondrial proteins which signifies oxidative damage [146]. These observations of oxidative damage in muscle support previous observations of free radical damage as a pathologic mechanism in CRPS [147-149]. Eight children with mitochondrial disease and probable CRPS have been described which also lends further support to a role of dysfunctional mitochondria as a possible mechanism of the muscle dysfunction that occurs in CRPS patients [150].

Bone and joint pain are suffered by a majority of CRPS patients. X-rays of the affected extremities demonstrate bone lakes (intracortical excavation) associated with periarticular, trabecular and periosteal demineralization and bone resorption [151]. These changes are thought to be the result of osteoclastic activation possibly from nociceptor release of substance P [152]. During bone resorption, activated osteoclasts reduce $\mathrm{pH}$ enough to depolarize pain afferents which densely innervate bone [151]. Magnetic resonance imaging often reveals bone marrow edema and triple phase bone scans demonstrate pooling in the late phase $[151,153]$ in $30 \%$ to $50 \%$ of patients. Pathologic fractures are very common in CRPS-I patients. A frequent fracture occurs in the $5^{\text {th }}$ metatarsal bone. Most patients suffer fractures during their usual activities or with minimal trauma. Experimental evidence demonstrates that bone formation and maintenance are critically dependent on an intact small fiber innervation which is dysfunctional in CRPS-I patients [2,154-156]. These fractures are difficult to heal which may also be a reflection of dysfunction of bone innervation.

\section{Endocrine System}

All patients with moderate to severe CRPS experience stress due to pain itself and the disruption of work, personal relationships and activities of daily living. In a longitudinal study of 270 patients, 69\% described severe tiredness and unusual fatigue. Disproportionate unexplained fatigue may be due to congestive heart failure, hepatic and renal failure, decreased systemic oxygenation (anemia or COPD), endocrine dysfunction (hypothyroidism, adrenal insufficiency), depression or inflammatory cytokine mediated illness (malignancy, human immunodeficiency, HIV, Epstein-Barr and other viral infections) and medications including narcotics. Twenty six patients with severe fatigue and total body CRPS underwent evaluation of their hypothalamic pituitary axis. Twenty three were females and 3 were males whose median age was 44 years (mean 43 years, range 20 to 64 years). No patient had anemia, congestive heart failure, COPD, renal or hepatic failure, HIV, malignancy or recent infec- tion. No patient had active major depression or had a history of recent steroid use. Low baseline cortisol levels were noted in ten of the twenty six patients - one of whom had a low TSH level. The adrenocorticotrophic hormone (ACTH) stimulation test was administered to patients with low baseline cortisol levels. All ten patients with low cortisol levels responded with a significant increase in serum cortisol within one hour. This implies normal adrenal gland function but an impaired hypothalamo-pituitary-adrenal [157] axis demonstrating tertiary adrenal insufficiency. In this ongoing study [158] approximately $38 \%$ of severe CRPS patients have a low serum cortisol level.

Experimental studies have demonstrated that systemic corticosterone suppressed the late phase of the formalin test which implies a role in control of central sensitization $[159,160]$ or inhibition of inflammatory mediators [161]. Further support that glucocorticoids mediate central effects in neuropathic pain is derived from models in which the development and maintenance of mechanical hyperalgesia and allodynia following nerve injury is decreased following systemic administration of be- tamethasone [162]. Glucocorticoids may decrease pain by several mechanisms: 1) Suppression of intracellular cascades mediated by phospholipase $A_{2}$ [163]; 2) Decreasing ectopic discharge from experimental neuromas; 3) Blocking neurotransmission in C fibers [164,165]; 4) Decreasing microglial activation [166]. Approximately $40 \%$ of CRPS patients have low cortisol levels which can be a component of their sustained pain.

Approximately one third of moderate to severe CRPS patients suffer hypothyroidism [1]. The effect of this deficit is not known other than that noted in Sudek's atrophy. Hyperparathyroid function and bone metabolism has not been reported.

The role of the HPA in chronic stress is well documented $[167,168]$. The above data that demonstrates low cortisol levels in a significant portion of CRPS patients with normal adrenal function after cosyntropin stimulation supports failure of the HPA axis in the illness.

A great percentage of patients with severe CRPS are treated with large doses of strong opiods. A recent study has demonstrated pituitary dysfunction in all of its axes with hypofunction of: 1) The hypothalamic-pituitary-gonadal axis; 2) Hyperfunction of the HPA axis; 3) Higher prolactin levels. Cessation of narcotics can reverse the endocrine dysfunction [169].

\section{Dermatologic Manifestations of CRPS}

In a longitudinal study of the natural history of CRPS $71 \%$ of patients reported skin color changes within 5 years that increased to $81 \%$ after 15 years. This was usually a combination of erythema, mottling, livedo reticularis and cyanosis [1]. Swelling was noted in $75 \%$ of pa- 
tients by the first year and in $90 \%$ of patients after 15 years [1]. A peculiar finding noted in several patients was the "ligature sign", as if the patient had tied a ligature around the edematous extremity that persisted even as edema decreased during treatment. Approximately $20 \%$ of patients report a slightly raised morbilliform rash. The most common lesion seen is a well circumscribed 1 $3 \mathrm{~mm}$ punched out ulcer-like lesion that is preceded by a pruritic skin lesion resembling an insect bite. Within 2 to 3 days, the center of the lesion is excavated and its circumference is raised. The pruritis ends at this stage. The lesion heals with an atrophic thin center and clearly erythematous margins. In an early publication, two of nine patients suffered recurrent bullae in their chronically edematous legs [170]. Ultrastructural evaluation of biopsy material from a bullous lesion in one patient revealed abnormalities in basement membrane and anchoring fibrils. In some areas the basement membrane did not contain any anchoring fibrils and segments of basement membrane revealed decreased electron density and focal disruption. Two patients demonstrated lesions similar to pigmented purpura. These patients had the acute onset of marked erythema in their chronically edematous leg. Biopsy revealed lymphocytes and histiocytes surrounding blood vessels with extravasted erythrocytes that most closely resembled Schamberg's disease [171]. After approximately two years, the skin of the affected extremity becomes atrophic, smooth and often dry. Brittleness, ridging and thinning of the nails occurs concomitantly. Verrucous changes often seen in patients with venous stasis do occur in addition to cellulitis and ulceration. A subset of these patients slough large areas of skin. Patients with bullae and evidence of disruption of collagenous anchoring fibrils had normal dermoepidermal immunofluorescence. The bullous eruption seen in these patients is similar to that described in diabetic patients with neuropathy [172-174].

There has been extensive pathologic study of the amputated limbs of 8 CRPS patients which revealed severe muscle atrophy and severely thickened capillaries as well as ultrastructural quantification of $\mathrm{C}$ fiber degeneration [149]. Two further anatomical studies of skin from amputated CRPS-I limbs revealed loss of endothelial integrity, blood vessel hypertrophy and reduced epidermal sweat gland and vascular small nerve fiber innervation. Altered neuropeptide profiles were noted in surviving small nociceptive fiber afferents that innervated hair follicles, superficial arterioles and sweat glands $[175,176]$. However, a recent study of much less severely affected patients found alterations of small fiber skin innervation in only $20 \%$ of CRPS-I patients. There were no patient signs or symptoms or stage of disease that predicted epidermal nerve density $[177,178]$. In this study there was no consistent reduction in sweat gland nerve fiber density. An abnormal dense small-fiber innervation around hair follicles has also been described in CRPS-I patients [175].

The trophic effects of CRPS-I are noted in skin, muscle, bone (Sudek's atrophy) and joints. The skin and integument atrophy is often particularly apparent in interphalangeal joints of the hand and the dorsum of the foot and lower leg in conjunction with brawny edema. The nails become thickened, ridged, grow too rapidly and split. Early in the course of the illness when it is often sympathetically maintained, hair becomes thicker, curly and grows more rapidly. As the disease progresses it is lost [114]. Experimental axotomy of cutaneous nerves decreases keratinocyte mitosis and results in epidermal thinning and hair loss [179,180].

The distal extremities and particularly the finger tips are pivotal for thermo-regulation affected by arteriovenous shunts [2]. The sympathetic innervation of these arterioles normally tonically constricts their smooth muscle which occludes the arteriovenous shunt (AVS). During the progression of CRPS-I there maybe nervi vasulorum degeneration (small fibers) which would allow blood to bypass nutritive capillaries and thus cause hypoxia of the perfused tissue (loss of skin, connective tissue and muscle). This mechanism has been suggested as a cause of the atrophy seen in the muscles of CRPS patients $[2,142]$.

Sweating abnormalities are seen in approximately 30\% of patients. In a large study of well characterized CRPS-I patients, 22\% had increased resting sweat output, 7\% decreased and in $71 \%$ it was normal [181]. Patients are often unaware of sweating abnormalities which fluctuate with emotional state and environmental stimuli. Denervated sweat glands that do not respond to neurologic stimuli may respond to circulating norepinephrine although their usual ligand is acetylcholine [117].

The Gardner Diamond syndrome is common in CRPS patients. Patients experience spontaneous bruising which often occurs months following an initial trauma [182]. The bruising occurs in areas that were not injured. The suggested mechanism is an autoimmune reaction against a component of the patient's erythrocytes. Coagulation parameters are normal and skin biopsy reveals nonspecific changes. Possible antigens that elicit this autoimmune response are thought to be phosphatidyl serine-a phosphoglyceride of the red blood cell membrane [183185]. Occasionally, deep muscle tissue is the site of erythrocyte extravasation. As noted earlier, the inflamematory response resulting in neurogenic edema may be a mechanism for red blood extravasation in CRPS [186, 187].

\section{Urological System}

Urological symptoms and signs are seen in approximately $25 \%$ of CRPS patients [1]. In a study of 20 consecutive CRPS patients who were referred to an academic urology service, the main complaints were frequency, 
urgency or urinary incontinence. The mean age of these patients was $43 \pm 10$ years and the duration of urological symptom was almost 5 years [188]. No patient had voiding problems prior to the onset of CRPS. Endoscopic evaluation of these patients was normal as was cytology. Renal ultrasound cleared upper tract pathology such as hydronephrosis, nephrolithisasis or tumor. Detrusor hyperreflexia was found in 8 patients, detrusor areflexia in 8 patients and sensory urgency in 3. Detrusor hyperreflexia with detrusor external sphincter dysnergia was documented in 1 patient. Four of the patients (women) had stress incontinence. The mean cystometric bladder capacity was $417 \pm 182 \mathrm{ml}$. Complex regional pain has been diagnosed in the penis one year following transurethral prostatectomy [189]. Pelvic and perineal pain is also seen in CRPS patients particularly if both lower extremities are affected $[114,190]$.

\section{Gastrointestinal System}

In the prospective study of 270 patients who were evaluated prior to ketamine infusion [1], constipation was reported most frequently (113 patients, 41\%). Common other symptoms were nausea (63 patients, 23.3\%), vomiting (31 patients, 11.5\%), complaints of intermittent diarrhea (18.5\%) and indigestion (18.5\%). Irritable bowel syndrome was diagnosed in 46 patients (17\%) since onset of CRPS.

Dysphagia was frequently noted (47 patients, 17.4\%) and has been thoroughly evaluated in over 20 patients. Patients typically describe a feeling of food being stuck in their throat. All patients were evaluated by an ENT and swallowing specialist. They underwent a comprehensive head and neck examination that included fiber-optic nasopharyngoscopy. The patients' swallowing function was evaluated with water, thickened juice (nectar, honey) and solids (cottage cheese). The swallowing parameters assessed were: 1) Bolus formation; 2) Initiation; 3) Delay; 4) Residual; 5) Clearance; 6) Spasm; 7) GERD. All patients had difficulty with bolus formation and control. They were slow to initiate swallow and had a significant delay with the bolus which collected at the valleculae for a prolonged period of time. Deglutition demonstrated poor clearance from the hypopharynx with multiple involuntary swallows. Laryngeal penetration and frank aspiration did not occur. The dysphagia experienced by these patients appears to be multifactorial. Inability to initiate movement of pharyngeal musculature causes poor bolus formation with consequent segmentation. Patients also appear to have diminished sensation of the bolus that leads to pooling within the vallecula, a delayed swallow and significant residual within the piriform sinus and poor pharyngeal clearance. GERD is common in the CRPS population (73\%). As noted, stress of many types is noted in these patients [191] and multi- ple medications may contribute to GERD specifically and dysphagia generally.

Gastroparesis is a major problem in almost all longstanding patients that have suffered more than 5 years with CRPS. In general, these patients have multi-limb disease; the lower extremities are affected to a greater extent than the upper and urological symptoms are concomitant. The most frequent complaint is early satiety and bloating. Severe constipation, diarrhea and irritable bowel symptomatology are present in $90 \%$ of these patients.

Pain from CRPS involvement on the right side is frequently mistaken for gall bladder disease leading to operation [13]. Although the pain emanates from the axilla and radiates to the anterior chest wall, lateral chest wall (gall bladder region) and may also be felt at the tip of the scapula, its most troubling feature maybe epigastric pain. This is most often diagnosed as GERD. Approximately $5 \%$ of our severe patients have had their gall bladder removed for pain caused by the ICB nerve on the right side.

Central sensitization syndrome (CSS), a pathophysiologic component of CRPS, is thought to be important in irritable bowel syndrome (IBS) and functional dyspepsia [192]. A closely related syndrome, fibromyalgia (FB), has been related to the metabolic syndrome in women [193]. FB is also associated with functional bowel disorders and cyclic vomiting syndrome (CVS) [194]. In a study of 18 adult patients with CVS, it was demonstrated that the strongest associations were FB and CRPS [195].

A recent study identified 8 children in seven families who suffered CRPS-I and also had additional gastrointestinal (GI) dysmotility and cyclic vomiting. All 7 children met the Nijmegen (2002) diagnostic criteria for mitochondrial disease and 6 of the 7 probands had probable maternal inheritance [150]. GI disorders are common in CRPS and detailed physiologic studies are in progress.

There is accumulating evidence that thinly myelinated $\mathrm{A}-\delta$ and unmyelinated $\mathrm{C}$ fibers are involved in the somatic manifestations of CRPS [2]. They may also involve internal organs such as the GI tract. Early evidence suggests gastroparesis is a component of the clinical manifestations of early satiety, bloating, nausea and vomiting reported by approximately $5 \%$ of patients [1].

Nociceptive $\mathrm{C}$ and $\mathrm{A}-\delta$ axons innervate blood vessels and their neuroeffector secretions can marginalize immunocytes into the intestinal wall. Lymphocyte, monocytes, and mast cells thus recruited may trigger a neuro-immune cycle of inflammation and vasogenic edema of the intestinal wall similar to their somatic effects [2]. Small fiber involvement and resulting gastroparesis are well documented in diabetics who have small fiber neuropathy [196]. Circulating systemic inflammatory cytokines have also been demonstrated to 
cause gut edema [197].

\section{Conclusion}

Almost all organ systems are involved during the course of CRPS. Major progress has been accomplished in understanding its mechanisms as regard to pain $[187,198]$ but little is known about its pleiotropic effects on internal organs which are frequently very perplexing to those that care for these patients.

\section{Acknowledgements}

The author would like to acknowledge the support given to research over the years by the Tilly Family Foundation for the Study of Complex Regional Pain Syndrome and the Emily Sunstein Foundation for the Study of Neuropathic Pain.

\section{REFERENCES}

[1] R. J. Schwartzman, K. L. Erwin and G. M. Alexander, "The Natural History of Complex Regional Pain Syndrome," The Clinical Journal of Pain, Vol. 25, No. 4, 2009, pp. 273-280. doi:10.1097/AJP.0b013e31818ecea5

[2] A. L Oaklander and H. L. Fields, "Is Reflex Sympathetic Dystrophy/Complex Regional Pain Syndrome Type I: A Small-Fiber Neuropathy?” Annals of Neurology, Vol. 65, No. 6, 2009, pp. 629-638. doi:10.1002/ana.21692

[3] R. N. Harden, S. Bruehl, B. S. Galer, S. Saltz, M. Bertram, M. Backonja, et al., "Complex Regional Pain Syndrome: Are the Iasp Diagnostic Criteria Valid and Sufficiently Comprehensive?” Pain, Vol. 83, No. 2, 1999, pp. 211219.

[4] S. Bruehl, R. N. Harden, B. S. Galer, S. Saltz, M. Backonja and M. Stanton-Hicks, "Complex Regional Pain Syndrome: Are There Distinct Subtypes and Sequential Stages of the Syndrome?” Pain, Vol. 95, No. 1-2, 2002, pp. 119-124.

[5] S. Bruehl, R. N. Harden, B. S. Galer, S. Saltz, M. Bertram, M. Backonja, et al., "External Validation of IASP Diagnostic Criteria for Complex Regional Pain Syndrome and Proposed Research Diagnostic Criteria. International Association for the Study of Pain,” Pain, Vol. 81, No. 1-2, 1999, pp. 147-154.

[6] R. N. Harden and S. Bruehl, "Diagnostic Criteria: The Statistical Derivation of the Four Criterion Factors,” In: P. R. Wilson, M. D. Stanton-Hicks and R. N. Harden, Eds., CRPS: Current Diagnosis and Therapy, IASP Press, Seattle, 2005, pp. 45-58.

[7] R. N. Harden, S. Bruehl, R. S. Perez, F. Birklein, J. Marinus, C. Maihofner, et al., "Validation of Proposed Diagnostic Criteria (the "Budapest Criteria”) for Complex Regional Pain Syndrome,” Pain, Vol. 150, No. 2, 2010, pp. 268-274. doi:10.1016/j.pain.2010.04.030

[8] P. H. Veldman and R. J. Goris, "Surgery on Extremities with Reflex Sympathetic Dystrophy,” Unfallchirurg, Vol. 98, No. 1, 1995, pp. 45-48.
[9] J. Maleki, A. A. LeBel, G. J. Bennett and R. J. Schwartzman, "Patterns of Spread in Complex Regional Pain Syndrome, Type I (Reflex Sympathetic Dystrophy)," Pain, Vol. 88, No. 3, 2000, pp. 259-266.

[10] O. Rommel, M. Gehling, R. Dertwinkel, K. Witscher, M. Zenz, J. P. Malin, et al., "Hemisensory Impairment in Patients with Complex Regional Pain Syndrome,” Pain, Vol. 80, No. 1-2, 1999, pp. 95-101.

[11] M. A. van Rijn, J. Marinus, H. Putter, S. R. Bosselaar, G. L. Moseley and J. J. van Hilten, "Spreading of Complex Regional Pain Syndrome: Not a Random Process,” Journal of Neural Transmission, Vol. 118, No. 9, 2011, pp. 1301-1309. doi:10.1007/s00702-011-0601-1

[12] R. J. Schwartzman and J. R. Grothusen, "Brachial Plexus Traction Injury: Quantification of Sensory Abnormalities,” Pain Medicine, Vol. 9, No. 7, 2008, pp. 950-957. doi:10.1111/j.1526-4637.2007.00394.X

[13] J. W. Rasmussen, J. R. Grothusen, A. L. Rosso and R. J. Schwartzman, "Atypical Chest Pain: Evidence of Intercostobrachial Nerve Sensitization in Complex Regional Pain Syndrome,” Pain Physician, Vol. 12, No. 5, 2009, pp. E329-E234.

[14] M. de Mos, A. G. de Bruijn, F. J. Huygen, J. P. Dieleman, B. H. Stricker and M. C. Sturkenboom, "The Incidence of Complex Regional Pain Syndrome: A Population-Based Study," Pain, Vol. 129, No. 1-2, 2007, pp. 12-20. doi:10.1016/j.pain.2006.09.008

[15] P. H. Veldman, H. M. Reynen, I. E. Arntz and R. J. Goris, "Signs and Symptoms of Reflex Sympathetic Dystrophy: Prospective Study of 829 Patients,” Lancet, Vol. 342, No. 8878, 1993, pp. 1012-1016.

[16] P. U. Dijkstra, J. W. Groothoff, H. J. Duis and J. H. Geertzen, "Incidence of Complex Regional Pain Syndrome Type I after Fractures of the Distal Radius," European Journal of Pain, Vol. 7, No. 5, 2003, pp. 457462.

[17] D. R. Bickerstaff and J. A. Kanis, "Algodystrophy: An Under-Recognized Complication of Minor Trauma," British Journal of Rheumatology, Vol. 33, No. 3, 1994, pp. 240-248.

[18] A. Zyluk, "The Natural History of Post-Traumatic Reflex Sympathetic Dystrophy,” Journal of Hand Surgery, Vol. 23, No. 1, 1998, pp. 20-23.

[19] P. Sandroni, L. M. Benrud-Larson, R. L. McClelland and P. A Low, "Complex Regional Pain Syndrome Type I: Incidence and Prevalence in Olmsted County, a Population-Based Study,” Pain, Vol. 103, No. 1-2, 2003, pp. 199-207.

[20] W. Janig and R. Baron, "Complex Regional Pain Syndrome: Mystery Explained?” Lancet Neurology, Vol. 2, No. 11, 2003, pp. 687-697.

[21] R. P. Hart, M. F. Martelli and N. D. Zasler, "Chronic Pain and Neuropsychological Functioning,” Neuropsychology Review, Vol. 10, No. 3, 2000, pp. 131-149.

[22] B. D. Dick and S. Rashiq, "Disruption of Attention and Working Memory Traces in Individuals with Chronic Pain," Anesthesia \& Analgesia, Vol. 104, No. 5, 2007, pp. 1223-1229. doi:10.1213/01.ane.0000263280.49786.f5 
[23] D. K. Weiner, T. E. Rudy, L. Morrow, J. Slaboda and S. Lieber, "The Relationship between Pain, Neuropsychological Performance, and Physical Function in Community-Dwelling Older Adults with Chronic Low Back Pain,” Pain Medicine, Vol. 7, No. 1, 2006, pp. 60-70. doi:10.1111/j.1526-4637.2006.00091.x

[24] J. F. Karp, C. F. Reynolds 3rd, M. A. Butters, M. A. Dew, S. Mazumdar, A. E. Begley, et al., "The Relationship between Pain and Mental Flexibility in Older Adult Pain Clinic Patients,” Pain Medicine, Vol. 7, No. 5, 2006, pp. 444-452. doi:10.1111/j.1526-4637.2006.00212.x

[25] R. N. Harden, S. Bruehl, M. Stanton-Hicks and P. R. Wilson, "Proposed New Diagnostic Criteria for Complex Regional Pain Syndrome,” Pain Medicine, Vol. 8, No. 4, 2007, pp. 326-331. doi:10.1111/j.1526-4637.2006.00169.x

[26] D. J. Libon, R. J. Schwartzman, J. Eppig, D. Wambach, E. Brahin, B. L. Peterlin, et al., "Neuropsychological Deficits Associated with Complex Regional Pain Syndrome," Journal of the International Neuropsychological Society, Vol. 16, No. 3, 2010, pp. 566-573. doi:10.1017/S1355617710000214

[27] D. Wechsler, "Wechsler Adult Intelligence Scale," 3rd Edition, The Psychological Corporation, San Antonio, 1997.

[28] M. Lamar, C. C. Price, D. J. Libon, D. L. Penney, E. Kaplan, M. Grossman, et al., "Alterations in Working Memory as a Function of Leukoaraiosis in Dementia," Neuropsychologia, Vol. 45, No. 2, 2007, pp. 245-254. doi:10.1016/j.neuropsychologia.2006.07.009

[29] M. Lamar, M. Catani, C. C. Price, K. M. Heilman and D. J. Libon, "The Impact of Region-Specific Leukoaraiosis on Working Memory Deficits in Dementia,” Neuropsychologia, Vol. 46, No. 10, 2008, pp. 2597-2601. doi:10.1016/j.neuropsychologia.2008.04.007

[30] E. A. Phelps, F. Hyder, A. M. Blamire and R. G. Shulman, "FMRI of the Prefrontal Cortex during Overt Verbal Fluency,” Neuroreport, Vol. 8, No. 2, 1997, pp. 561-565.

[31] E. Kaplan, H. Goodglass and S. Weintrab, “The Boston Naming Test,” 2nd Edition, Lea \& Febiger, Philadelphia, 1983.

[32] J. A. Gladsjo, C. C. Schuman, J. D. Evans, G. M. Peavy, S. W. Miller and R. K. Heaton, "Norms for Letter and Category Fluency: Demographic Corrections for Age, Education, and Ethnicity,” Assessment, Vol. 6, No. 2, 1999, pp. 147-178.

[33] C. J. Mummery, K. Patterson, J. R. Hodges and R. J. Wise, “Generating 'Tiger' as an Animal Name or a Word Beginning with T: Differences in Brain Activation," Proceedings of the Royal Society, Vol. 263, No. 1373, 1996, pp. 989-995. doi:10.1098/rspb.1996.0146

[34] D. J. Libon, C. McMillan, D. Gunawardena, C. Powers, L. Massimo, A. Khan, et al., "Neurocognitive Contributions to Verbal Fluency Deficits in Frontotemporal Lobar Degeneration,” Neurology, Vol. 73, No. 7, 2009, pp. 535542. doi:10.1212/WNL.0b013e3181b2a4f5

[35] D. C. Delis, J. H. Kramer, E. Kaplan and B. A. Ober, "California Verbal Learning Test,” 2nd Edition, Psycho- logical Corporation, San Antonio, 2000.

[36] R. Melzack, “The Short-Form McGill Pain Questionnaire,” Pain, Vol. 30, No. 2, 1987, pp. 191-197.

[37] A. T. Beck, R. A. Steer and G. K. Brown, "Manual for the Beck Depression Inventory-II,” Psychological Corporation, San Antonio, 1996.

[38] C. C. Price, K. D. Garrett, A. L. Jefferson, S. Cosentino, J. J. Tanner, D. L. Penney, et al., "Leukoaraiosis Severity and List-Learning in Dementia," Clinical Neuropsychology, Vol. 23, No. 6, 2009, pp. 944-961. doi:10.1080/13854040802681664

[39] R. T. Kiefer, P. Rohr, K. Unertl, K. H. Altemeyer, J. Grothusen and R. J. Schwartzman, "Recovery from Intractable Complex Regional Pain Syndrome Type I (RSD) under High-Dose Intravenous Ketamine-Midazolam Sedation," Neurology, Vol. 58, No. 7, 2002, pp. A474A475.

[40] S. P. Koffler, B. M. Hampstead, F. Irani, J. Tinker, R. T. Kiefer, P. Rohr, et al., "The Neurocognitive Effects of 5 Day Anesthetic Ketamine for the Treatment of Refractory Complex Regional Pain Syndrome," Archives of Clinical Neuropsychology, Vol. 22, No. 6, 2007, pp. 719-729. doi:10.1016/j.acn.2007.05.005

[41] C. Maihofner, H. O. Handwerker, B. Neundorfer and F. Birklein, "Patterns of Cortical Reorganization in Complex Regional Pain Syndrome,” Neurology, Vol. 61, No. 12, 2003, pp. 1707-1715.

[42] C. Maihofner, H. O. Handwerker, B. Neundorfer and F. Birklein, "Cortical Reorganization during Recovery from Complex Regional Pain Syndrome,” Neurology, Vol. 63, No. 4, 2004, pp. 693-701. doi:63/4/693

[43] B. Pleger, M. Tegenthoff, P. Ragert, A. F. Forster, H. R. Dinse, P. Schwenkreis, et al., "Sensorimotor Retuning [Corrected] in Complex Regional Pain Syndrome Parallels Pain Reduction,” Annals of Neurology, Vol. 57, No. 3, 2005, pp. 425-429. doi:10.1002/ana.20394

[44] E. Peltz, F. Seifert, S. Lanz, R. Muller and C. Maihofner, "Impaired Hand Size Estimation in CRPS," Journal of Pain, Vol. 12, No. 10, 2011, pp. 1095-1101. doi:10.1016/j.jpain.2011.05.001

[45] J. S. Lewis, P. Kersten, K. M. McPherson, G. J. Taylor, N. Harris, C. S. McCabe, et al., "Wherever Is My Arm? Impaired Upper Limb Position Accuracy in Complex Regional Pain Syndrome,” Pain, Vol. 149, No. 3, 2010, pp. 463-469. doi:10.1016/j.pain.2010.02.007

[46] S. Forderreuther, U. Sailer and A. Straube, "Impaired Self-Perception of the Hand in Complex Regional Pain Syndrome (CRPS)," Pain, Vol. 110, No. 3, 2004, pp. 756761. doi:10.1016/j.pain.2004.05.019

[47] J. Frettloh, M. Huppe and C. Maier, "Severity and Specificity of Neglect-Like Symptoms in Patients with Complex Regional Pain Syndrome (CRPS) Compared to Chronic Limb Pain of Other Origins,” Pain, Vol. 124, No. 1-2, 2006, pp. 184-189. doi:10.1016/j.pain.2006.04.010

[48] B. Pleger, P. Ragert, P. Schwenkreis, A. F. Forster, C. Wilimzig, H. Dinse, et al., "Patterns of Cortical Reorganization Parallel Impaired Tactile Discrimination and Pain Intensity in Complex Regional Pain Syndrome," 
Neuroimage, Vol. 32, No. 2, 2006, pp. 503-510. doi:10.1016/j.neuroimage.2006.03.045

[49] A. Lebel, L. Becerra, D. Wallin, E. A. Moulton, S. Morris, G. Pendse, et al., "fMRI Reveals Distinct Cns Processing during Symptomatic and Recovered Complex Regional Pain Syndrome in Children," Brain, Vol. 131, No. 7, 2008, pp. 1854-1879. doi:10.1093/brain/awn123

[50] G. Robinson, H. Cohen and A. Goebel, "A Case of Complex Regional Pain Syndrome with Agnosia for Object Orientation,” Pain, Vol. 152, No. 7, 2011, pp. 1674-1681. doi:10.1016/j.pain.2011.02.010

[51] C. Maihofner, R. Baron, R. DeCol, A. Binder, F. Birklein, G. Deuschl, et al., "The Motor System Shows Adaptive Changes in Complex Regional Pain Syndrome," Brain, Vol. 130, No. 10, 2007, pp. 2671-2687. doi:10.1093/brain/awm131

[52] A. May, "Chronic Pain May Change the Structure of the Brain,” Pain, Vol. 137, No. 1, 2008, pp. 7-15. doi:10.1016/j.pain.2008.02.034

[53] A. V. Apkarian, Y. Sosa, S. Sonty, R. M. Levy, R. N. Harden, T. B. Parrish, et al., "Chronic Back Pain Is Associated with Decreased Prefrontal and Thalamic Gray Matter Density," Journal of Neuroscience, Vol. 24, No. 46, 2004, pp. 10410-10415. doi:10.1523/JNEUROSCI.2541-04.2004

[54] P. G. Patil, J. L. Apfelbaum and J. P. Zacny, "Effects of a Cold-Water Stressor on Psychomotor and Cognitive Functioning in Humans,” Physiology \& Behavior, Vol. 58, No. 6, 1995, pp. 1281-1286.

[55] N. Terrando, L. I. Eriksson, J. K. Ryu, T. Yang, C. Monaco, M. Feldmann, et al., "Resolving Postoperative Neuroinflammation and Cognitive Decline," Annals of Neurology, Vol. 70, No. 6, 2011, pp. 986-995. doi:10.1002/ana.22664

[56] Y. Arima, M. Harada, D. Kamimura, J. H. Park, F. Kawano, F. E. Yull, et al., "Regional Neural Activation Defines a Gateway for Autoreactive T Cells to Cross the Blood-Brain Barrier,” Cell, Vol. 148, No. 3, 2012, pp. 447-457. doi:10.1016/j.cell.2012.01.022

[57] F. Marchand, M. Perretti and S. B. McMahon, "Role of the Immune System in Chronic Pain," Nature Reviews Neuroscience, Vol. 6, No. 7, 2005, pp. 521-532. doi:10.1038/nrn1700

[58] F. J. Huygen, N. Ramdhani, A. van Toorenenbergen, J. Klein and F. J. Zijlstra, "Mast Cells Are Involved in Inflammatory Reactions during Complex Regional Pain Syndrome Type 1,” Immunology Letters, Vol. 91, No. 2-3, 2004, pp. 147-154. doi:10.1016/j.imlet.2003.11.013

[59] J. G. Groeneweg, F. J. Huygen, C. Heijmans-Antonissen, S. Niehof and F J. Zijlstra, "Increased Endothelin-1 and Diminished Nitric Oxide Levels in Blister Fluids of Patients with Intermediate Cold Type Complex Regional Pain Syndrome Type 1,” BMC Musculoskeletal Disorders, Vol. 7, No. 2006, p. 91. doi:10.1186/1471-2474-7-91

[60] F. Wesseldijk, D. Fekkes, F. J. Huygen, M. van de Heide-Mulder and F. J. Zijlstra, "Increased Plasma Glutamate, Glycine, and Arginine Levels in Complex Regional Pain Syndrome Type 1," Acta Anaesthesiologica Scandinavica, Vol. 52, No. 5, 2008, pp. 688-694.

\section{doi:10.1111/j.1399-6576.2008.01638.x}

[61] H. H. Kramer, T. Eberle, N. Uceyler, I. Wagner, T. Klonschinsky, L. P. Muller, et al., "TNF-Alpha in CRPS and 'Normal' Trauma-Significant Differences between Tissue and Serum," Pain, Vol. 152, No. 2, 2011, pp. 285-290. doi:10.1016/j.pain.2010.09.024

[62] N. Uceyler, J. P. Rogausch, K. V. Toyka and C. Sommer, "Differential Expression of Cytokines in Painful and Painless Neuropathies,” Neurology, Vol. 69, No. 1, 2007, pp. 42-49. doi:10.1212/01.wnl.0000265062.92340.a5

[63] G. M. Alexander, M. A. van Rijn, J. J. van Hilten, M. J. Perreault and R. J. Schwartzman, "Changes in Cerebrospinal Fluid Levels of Pro-Inflammatory Cytokines in CRPS,” Pain, Vol. 116, No. 3, 2005, pp. 213-219. doi:10.1016/j.pain.2005.04.013

[64] G. M. Alexander, M. J. Perreault, E. R. Reichenberger and R. J. Schwartzman, "Changes in Immune and Glial Markers in the Csf of Patients with Complex Regional Pain Syndrome," Brain, Behavior, and Immunity, Vol. 21, No. 5, 2007, pp. 668-676. doi:10.1016/j.bbi.2006.10.009

[65] F. J. Huygen, A. G. de Bruijn, J. Klein and F. J. Zijlstra, "Neuroimmune Alterations in the Complex Regional Pain Syndrome," European Journal of Pharmacology, Vol. 429, No. 1-3, 2001, pp. 101-113.

[66] B. W. Ritz, G. M. Alexander, S. Nogusa, M. J. Perreault, B. L. Peterlin, J. R. Grothusen, et al., "Elevated Blood Levels of Inflammatory Monocytes (CD14(+) CD16(+)) in Patients with Complex Regional Pain Syndrome," Clinical \& Experimental Immunology, Vol. 164, No. 1, 2011, pp. 108-117. doi:10.1111/j.1365-2249.2010.04308.x

[67] F. Blaes, K. Schmitz, M. Tschernatsch, M. Kaps, I. Krasenbrink, G. Hempelmann, et al., "Autoimmune Etiology of Complex Regional Pain Syndrome (M. Sudeck)," Neurology, Vol. 63, No. 9, 2004, pp. 1734-1736.

[68] D. Kohr, M. Tschernatsch, K. Schmitz, P. Singh, M. Kaps, K. H. Schafer, et al., "Autoantibodies in Complex Regional Pain Syndrome Bind to a Differentiation-Dependent Neuronal Surface Autoantigen,” Pain, Vol. 143, No. 3, 2009, pp. 246-251. doi:10.1016/j.pain.2009.03.009

[69] L. R. Watkins and S. F. Maier, "The Pain of Being Sick: Implications of Immune-to-Brain Communication for Understanding Pain,” Annual Review of Psychology, Vol. 51, No. 2000, 2000, pp. 29-57. doi:10.1146/annurev.psych.51.1.29

[70] L. E. Goehler, R. P. Gaykema, S. E. Hammack, S. F. Maier and L. R. Watkins, "Interleukin-1 Induces c-Fos Immunoreactivity in Primary Afferent Neurons of the Vagus Nerve,” Brain Research, Vol. 804, No. 2, 1998, pp. 306-310.

[71] L. E. Goehler, R. P. Gaykema, K. T. Nguyen, J. E. Lee, F. J. Tilders, S. F. Maier, et al., "Interleukin-1Beta in Immune Cells of the Abdominal Vagus Nerve: A Link between the Immune and Nervous Systems?” Journal of Neuroscience, Vol. 19, No. 7, 1999, pp. 2799-2806.

[72] L. R. Watkins and S. F. Maier, "Implications of Immuneto-Brain Communication for Sickness and Pain," Proceedings of the National Academy of Sciences USA, Vol. 96, No. 14, 1999, pp. 7710-7713. 
[73] H. E. Romeo, D. L. Tio, S. U. Rahman, F. Chiappelli and A. N. Taylor, "The Glossopharyngeal Nerve as a Novel Pathway in Immune-to-Brain Communication: Relevance to Neuroimmune Surveillance of the Oral Cavity," Journal of Neuroimmunology, Vol. 115, No. 1-2, 2001, pp. 91-100.

[74] S. Laye, R. M. Bluthe, S. Kent, C. Combe, C. Medina, P. Parnet, et al., "Subdiaphragmatic Vagotomy Blocks Induction of Il-1 Beta Mrna in Mice Brain in Response to Peripheral LPS,” American Journal of Physiology, Vol. 268, No. 5, 1995, pp. R1327-R1331.

[75] P. Mason, "Lipopolysaccharide Induces Fever and Decreases Tail Flick Latency in Awake Rats,” Neuroscience Letters, Vol. 154, No. 1-2, 1993, pp. 134-136.

[76] L. R. Watkins, L. E. Goehler, J. Relton, M. T. Brewer and S. F. Maier, "Mechanisms of Tumor Necrosis FactorAlpha (Tnf-Alpha) Hyperalgesia,” Brain Research, Vol. 692, No. 1-2, 1995, pp. 244-250.

[77] L. R. Watkins, L. E. Goehler, J. K. Relton, N. Tartaglia, L. Silbert, D. Martin, et al., "Blockade of Interleukin-1 Induced Hyperthermia by Subdiaphragmatic Vagotomy: Evidence for Vagal Mediation of Immune-Brain Communication,” Neuroscience Letters, Vol. 183, No. 1-2, 1995, pp. 27-31.

[78] J. A. Smith, D. G. Karalis, A. L. Rosso, J. R. Grothusen, S. E. Hessen and R. J. Schwartzman, "Syncope in Complex Regional Pain Syndrome,” Clinical Cardiology, Vol. 34, No. 4, 2011, pp. 222-225. doi:10.1002/clc.20879

[79] M. Brignole, C. Menozzi, A. Del Rosso, S. Costa, G. Gaggioli, N. Bottoni, et al., "New Classification of Haemodynamics of Vasovagal Syncope: Beyond the VASIS Classification. Analysis of the Pre-Syncopal Phase of the Tilt Test without and with Nitroglycerin Challenge. Vasovagal Syncope International Study,” Europace, Vol. 2, No. 1, 2000, pp. 66-76.

[80] A. J. Aerts and P. Dendale, "Diagnostic Value of Nitrate Stimulated Tilt Testing without Preceding Passive Tilt in Patients with Suspected Vasovagal Syncope and a Healthy Control Group,” Pacing and Clinical Electrophysiology, Vol. 28, No. 1, 2005, pp. 29-32. doi:10.1111/j.1540-8159.2005.09439.x

[81] F. Radrigan, E. Dumas, G. Chamorro, P. Casanegra and J. Jalil, "Head-Up Tilt Test in Healthy Asymptomatic Patients,” Revista Medica de Chile, Vol. 124, No. 10, 1996, pp. 1187-1191.

[82] B. P. Grubb, D. Kosinski, P. Temesy-Armos and P. Brewster, "Responses of Normal Subjects during 80 Degrees Head Upright Tilt Table Testing with and without Low Dose Isoproterenol Infusion," Pacing and Clinical Electrophysiology, Vol. 20, No. 8, 1997, pp. 2019-2023.

[83] C. Podoleanu, A. Frigy, D. Dobreanu, S. Micu, D. Podoleanu, A. Incze, et al., "Study of the Efficiency of the Head-Up Tilt Test with Nitroglycerin Challenge in the Diagnosis of Vasovagal Syncope," Romanian Journal of Internal Medicine-Revue Roumaine de Medecine Interne, Vol. 42, No. 3, 2004, pp. 585-594.

[84] P. M. Meier, M. E. Alexander, N. F. Sethna, C. C. De Jong-De Vos Van Steenwijk, D. Zurakowski and C. B. Berde, “Complex Regional Pain Syndromes in Children and Adolescents: Regional and Systemic Signs and Symptoms and Hemodynamic Response to Tilt Table Testing,” The Clinical Journal of Pain, Vol. 22, No. 4, 2006, pp. 399-406. doi:10.1097/01.ajp.0000192514.50955.d6

[85] A. J. Terkelsen, M. Holgaard, J. Hansen, N. B. Finnerup, K. Kroner and T. S. Jensen, "Heart Rate Variability in Complex Regional Pain Syndrome during Rest and Mental and Orthostatic Stress,” Anesthesiology, Vol. 116, No. 1, 2012, pp. 133-146. doi:10.1097/ALN.0b013e31823bbfb0

[86] D. L. Eckberg, "Physiological Basis for Human Autonomic Rhythms," Annals of Medicine, Vol. 32, No. 5, 2000, pp. 341-349.

[87] E. M. Holper and D. P. Faxon, "Percutaneous Coronary Intervention in Women," Journal of the American Medical Women's Association, Vol. 58, No. 4, 2003, pp. $264-$ 271.

[88] J. M. DeCara, "Noninvasive Cardiac Testing in Women," Journal of the American Medical Women's Association, Vol. 58, No. 4, 2003, pp. 254-263.

[89] G. Pontone, D. Andreini, G. Ballerini, E. Nobili and M. Pepi, "Diagnostic Work-Up of Unselected Patients with Suspected Coronary Artery Disease: Complementary Role of Multidetector Computed Tomography, Symptoms and Electrocardiogram Stress Test," Coronary Artery Disease, Vol. 18, No. 4, 2007, pp. 265-274. doi:10.1097/MCA.0b013e328035f8ae

[90] M. E. Goldberg, R. J. Schwartzman, R. Domsky, M. Sabia and M. C. Torjman, "Deep Cervical Plexus Block for the Treatment of Cervicogenic Headache,” Pain Physician, Vol. 11, No. 6, 2008, pp. 849-854.

[91] C. J. Woolf and M. W. Salter, "Neuronal Plasticity: Increasing the Gain in Pain,” Science, Vol. 288, No. 5472, 2000, pp. 1765-1769.

[92] M. G. O’Rourke, T. S. Tang, S. I. Allison and W. Wood, "The Anatomy of the Extrathoracic Intercostobrachial Nerve," The Australian and New Zealand Journal of Surgery, Vol. 69, No. 12, 1999, pp. 860-864.

[93] M. Loukas, R. G. Louis Jr., Q. A. Fogg, B. Hallner and A. A. Gupta, "An Unusual Innervation of Pectoralis Minor and Major Muscles from a Branch of the Intercostobrachial Nerve," Clinical Anatomy, Vol. 19, No. 4, 2006, pp. 347-349. doi:10.1002/ca.20284

[94] M. Loukas, J. Hullett, R. G. Louis Jr., S. Holdman and D. Holdman, "The Gross Anatomy of the Extrathoracic Course of the Intercostobrachial Nerve," Clinical Anatomy, Vol. 19, No. 2, 2006, pp. 106-111. doi:10.1002/ca.20226

[95] M. Loukas, R. G. Louis Jr. and C. T. Wartmann, “T2 Contributions to the Brachial Plexus,” Neurosurgery, Vol. 60, No. 2, 2007, pp. ONS13-ONS18. doi:10.1227/01.NEU.0000249234.20484.2A

[96] K. O. Taylor, "Morbidity Associated with Axillary Surgery for Breast Cancer,” ANZ Journal of Surgery, Vol. 74, No. 5, 2004, pp. 314-317. doi:10.1111/j.1445-1433.2004.02992.x

[97] R. B. Steinberg and K. Stueber, "Sympathetically Mediated Pain after Reduction Mammoplasty: An Unusual 
Complication,” Journal of Clinical Anesthesia, Vol. 10, No. 3, 1998, pp. 246-248.

[98] F. A. Papay, A. Verghese, M. Stanton-Hicks and J. Zins, "Complex Regional Pain Syndrome of the Breast in a Patient after Breast Reduction," Annals of Plastic Surgery, Vol. 39, No. 4, 1997, pp. 347-352.

[99] R. J. Schwartzman and J. Kerrigan, "The Movement Disorder of Reflex Sympathetic Dystrophy,” Neurology, Vol. 40, No. 1, 1990, pp. 57-61.

[100] G. D. Schott, "Peripherally-Triggered CRPS and Dystonia,” Pain, Vol. 130, No. 3, 2007, pp. 203-207. doi:10.1016/i.pain.2007.04.013

[101] M. A. van Rijn, J. Marinus, H. Putter and J. J. van Hilten, "Onset and Progression of Dystonia in Complex Regional Pain Syndrome,” Pain, Vol. 130, No. 3, 2007, pp. 287293. doi:10.1016/j.pain.2007.03.027

[102] J. J. Van Hilten, H. P. D. Blumberg and R. J. Schwartzman, "Factor IV: Movement Disorders and Dystrophy: Clinical and Pathophysiological Aspects,” In: P. R. Wilson, M. Stanton-Hicks and R. N. Harden, Eds., CRPS: Current Diagnosis and Therapy, IASP Press, Seattle, 2005.

[103] D. J. Irwin and R. J. Schwartzman, “Complex Regional Pain Syndrome with Associated Chest Wall Dystonia: A Case Report," Journal of Brachial Plexus and Peripheral Nerve Injury, Vol. 6, No. 2011, p. 6. doi:10.1186/1749-7221-6-6

[104] E. K. Krumova, J. Frettloh, S. Klauenberg, H. Richter, G. Wasner and C. Maier, "Long-Term Skin Temperature Measurements-A Practical Diagnostic Tool in Complex Regional Pain Syndrome,” Pain, Vol. 140, No. 1, 2008, pp. 8-22. doi:10.1016/j.pain.2008.07.003

[105] G. Wasner, J. Schattschneider, K. Heckmann, C. Maier and R. Baron, "Vascular Abnormalities in Reflex Sympathetic Dystrophy (Crps I): Mechanisms and Diagnostic Value,” Brain, Vol. 124, No. 3, 2001, pp. 587-599.

[106] G. Wasner, K. Heckmann, C. Maier and R. Baron, "Vascular Abnormalities in Acute Reflex Sympathetic Dystrophy (Crps I): Complete Inhibition of Sympathetic Nerve Activity with Recovery," Archives of Neurology, Vol. 56, No. 5, 1999, pp. 613-620.

[107] J. M. Arnold, R. W. Teasell, A. P. MacLeod, J. E. Brown and S. G. Carruthers, "Increased Venous Alpha-Adrenoceptor Responsiveness in Patients with Reflex Sympathetic Dystrophy," Annals of Internal Medicine, Vol. 118, No. 8, 1993, pp. 619-621.

[108] P. D. Drummond, S. Skipworth and P. M. Finch, “Alpha 1-Adrenoceptors in Normal and Hyperalgesic Human Skin,” Clinical Science (Lond), Vol. 91, No. 1, 1996, pp. 73-77.

[109] T. Eberle, B. Doganci, H. H. Kramer, C. Geber, M. Fechir, W. Magerl, et al., "Warm and Cold Complex Regional Pain Syndromes: Differences beyond Skin Temperature?” Neurology, Vol. 72, No. 6, 2009, pp. 505-512. doi:10.1212/01.wnl.0000341930.35494.66

[110] M. D. Bej and R. J. Schwartzman, “Abnormalities of Cutaneous Blood Flow Regulation in Patients with Reflex Sympathetic Dystrophy as Measured by Laser Doppler
Fluxmetry,” Archives of Neurology, Vol. 48, No. 9, 1991, pp. 912-915.

[111] M. Schurmann, G. Gradl, H. J. Andress, H. Furst and F. W. Schildberg, “Assessment of Peripheral Sympathetic Nervous Function for Diagnosing Early Post-Traumatic Complex Regional Pain Syndrome Type I,” Pain, Vol. 80, No. 1-2, 1999, pp. 149-159.

[112] G. Gradl and M. Schurmann, "Sympathetic Dysfunction as a Temporary Phenomenon in Acute Posttraumatic CRPS I,” Clinical Autonomic Research, Vol. 15, No. 1, 2005, pp. 29-34. doi:10.1007/s10286-005-0237-z

[113] M. Di Benedetto, C. W. Huston, M. W. Sharp and B. Jones, "Regional Hypothermia in Response to Minor Injury,” American Journal of Physical Medicine \& Rehabilitation-Association of Academic Physiatrists, Vol. 75, No. 4, 1996, pp. 270-277.

[114] R. J. Schwartzman and T. L. McLellan, "Reflex Sympathetic Dystrophy. A Review,” Archives of Neurology, Vol. 44, No. 5, 1987, pp. 555-561.

[115] A. J. Terkelsen, F. W. Bach and T. S. Jensen, "Experimental Forearm Immobilization in Humans Induces Cold and Mechanical Hyperalgesia,” Anesthesiology, Vol. 109, No. 2, 2008, pp. 297-307. doi:10.1097/ALN.0b013e31817f4c9d

[116] T. C. Chelimsky, P. A. Low, J. M. Naessens, P. R. Wilson, P. C. Amadio and P. C. O’Brien, "Value of Autonomic Testing in Reflex Sympathetic Dystrophy," Mayo Clinic Proceedings, Vol. 70, No. 11, 1995, pp. 1029-1040. doi:10.1016/S0025-6196(11)64438-8

[117] K. R. Chemali, R. Gorodeski and T. C. Chelimsky, “Alpha-Adrenergic Supersensitivity of the Sudomotor Nerve in Complex Regional Pain Syndrome," Annals of $\mathrm{Neu}$ rology, Vol. 49, No. 4, 2001, pp. 453-459.

[118] R. Baron, J. Schattschneider, A. Binder, D. Siebrecht and G. Wasner, "Relation between Sympathetic Vasoconstrictor Activity and Pain and Hyperalgesia in Complex Regional Pain Syndromes: A Case-Control Study," Lancet, Vol. 359, No. 9318, 2002, pp. 1655-1660. doi:10.1016/S0140-6736(02)08589-6

[119] R. J. Schwartzman, "The Autonomic Nervous System and Pain,” In: O. Appenzeller, Ed., Handbook of Clinical Neurology the Autonomic Nervous System Part II Dysfunctions, Elsevier Science, Amsterdam, 2000, pp. 309347.

[120] P. D. Drummond, P. M. Finch, S. Skipworth and P. Blockey, "Pain Increases during Sympathetic Arousal in Patients with Complex Regional Pain Syndrome," Neurology, Vol. 57, No. 7, 2001, pp. 1296-1303.

[121] T. J. Coderre, D. N. Xanthos, L. Francis and G. J. Bennett, "Chronic Post-Ischemia Pain (CPIP): A Novel Animal Model of Complex Regional Pain Syndrome-Type I (CRPS-I; Reflex Sympathetic Dystrophy) Produced by Prolonged Hindpaw Ischemia and Reperfusion in the Rat,” Pain, Vol. 112, No. 1-2, 2004, pp. 94-105. doi:10.1016/j.pain.2004.08.001

[122] P. E. Molina, "Noradrenergic Inhibition of TNF Upregulation in Hemorrhagic Shock," Neuroimmunomodulation, Vol. 9, No. 3, 2001, pp. 125-133. 
[123] P. E. Molina, "Neurobiology of the Stress Response: Contribution of the Sympathetic Nervous System to the Neuroimmune Axis in Traumatic Injury,” Shock, Vol. 24, No. 1, 2005, pp. 3-10.

[124] C. Sommer and M. Kress, "Recent Findings on How Proinflammatory Cytokines Cause Pain: Peripheral Mechanisms in Inflammatory and Neuropathic Hyperalgesia," Neuroscience Letters, Vol. 361, No. 1-3, 2004, pp. 184-187. doi:10.1016/j.neulet.2003.12.007

[125] S. Pezet and S. B. McMahon, "Neurotrophins: Mediators and Modulators of Pain," Annual Review of Neuroscience, Vol. 29, No. 2006, 2006, pp. 507-538. doi:10.1146/annurev.neuro.29.051605.112929

[126] S. England, S. Bevan and R. J. Docherty, "PGE2 Modulates the Tetrodotoxin-Resistant Sodium Current in Neonatal Rat Dorsal Root Ganglion Neurones via the Cyclic AMP-Protein Kinase a Cascade,” Journal of Physiology, Vol. 495, No. 1996, pp. 429-440.

[127] A. Opree and M. Kress, "Involvement of the Proinflammatory Cytokines Tumor Necrosis Factor-Alpha, Il-1 Beta, and Il-6 but Not Il-8 in the Development of Heat Hyperalgesia: Effects on Heat-Evoked Calcitonin GeneRelated Peptide Release from Rat Skin,” Journal of Neuroscience, Vol. 20, No. 16, 2000, pp. 6289-6293.

[128] H. Vedder, H. U. Affolter and U. Otten, "Nerve Growth Factor (NGF) Regulates Tachykinin Gene Expression and Biosynthesis in Rat Sensory Neurons during Early Postnatal Development,” Neuropeptides, Vol. 24, No. 6, 1993, pp. 351-357.

[129] P. Holzer, "Neurogenic Vasodilatation and Plasma Leakage in the Skin," General Pharmacology, Vol. 30, No. 1, 1998, pp. 5-11.

[130] F. Birklein, M. Schmelz, S. Schifter and M. Weber, "The Important Role of Neuropeptides in Complex Regional Pain Syndrome," Neurology, Vol. 57, No. 12, 2001, pp. 2179-2184.

[131] C. Schinkel, A. Gaertner, J. Zaspel, S. Zedler, E. Faist and M. Schuermann, "Inflammatory Mediators Are Altered in the Acute Phase of Posttraumatic Complex Regional Pain Syndrome," The Clinical Journal of Pain, Vol. 22, No. 3, 2006, pp. 235-239. doi:10.1097/01.ajp.0000169669.70523.f0

[132] S. Leis, M. Weber, A. Isselmann, M. Schmelz and F. Birklein, "Substance-P-Induced Protein Extravasation Is Bilaterally Increased in Complex Regional Pain Syndrome,” Experimental Neurology, Vol. 183, No. 1, 2003, pp. 197-204.

[133] S. Leis, M. Weber, M. Schmelz and F. Birklein, "Facilitated Neurogenic Inflammation in Unaffected Limbs of Patients with Complex Regional Pain Syndrome,” Neuroscience Letters, Vol. 359, No. 3, 2004, pp. 163-166. doi:10.1016/j.neulet.2004.02.025

[134] M. Weber, F. Birklein, B. Neundorfer and M. Schmelz, "Facilitated Neurogenic Inflammation in Complex Regional Pain Syndrome,” Pain, Vol. 91, No. 3, 2001, pp. 251-257.

[135] A. Dallos, M. Kiss, H. Polyanka, A. Dobozy, L. Kemeny and S. Husz, "Effects of the Neuropeptides Substance P,
Calcitonin Gene-Related Peptide, Vasoactive Intestinal Polypeptide and Galanin on the Production of Nerve Growth Factor and Inflammatory Cytokines in Cultured Human Keratinocytes,” Neuropeptides, Vol. 40, No. 4, 2006, pp. 251-263. doi:10.1016/j.npep.2006.06.002

[136] W. S. Kingery, "Role of Neuropeptide, Cytokine, and Growth Factor Signaling in Complex Regional Pain Syndrome," Pain Medicine, Vol. 11, No. 8, 2010, pp. 12391250. doi:10.1111/j.1526-4637.2010.00913.x

[137] F. Wesseldijk, F. J. Huygen, C. Heijmans-Antonissen, S. P. Niehof and F. J. Zijlstra, "Tumor Necrosis Factor-Alpha and Interleukin-6 Are Not Correlated with the Characteristics of Complex Regional Pain Syndrome Type 1 in 66 Patients," European Journal of Pain, Vol. 12, No. 6, 2008, pp. 716-721. doi:10.1016/j.ejpain.2007.10.010

[138] C. Maihofner, H. O. Handwerker, B. Neundorfer and F. Birklein, "Mechanical Hyperalgesia in Complex Regional Pain Syndrome: A Role for TNF-Alpha?” Neurology, Vol. 65, No. 2, 2005, pp. 311-313. doi:10.1212/01.wnl.0000168866.62086.8f

[139] R. J. Schwartzman, G. M. Alexander and J. Grothusen, "The Use of Ketamine in Complex Regional Pain Syndrome: Possible Mechanisms,” Expert Review of Neurotherapeutics, Vol. 11, No. 5, 2011, pp. 719-734.

[140] N. M. Hulsman, J. H. Geertzen, P. U. Dijkstra, J. J. van den Dungen and W. F. den Dunnen, "Myopathy in CRPSI: Disuse or Neurogenic?” European Journal of Pain, Vol. 13, No. 7, 2009, pp. 731-736. doi:10.1016/j.ejpain.2008.09.006

[141] T. Klimova and N. S. Chandel, "Mitochondrial Complex III Regulates Hypoxic Activation of HIF," Cell Death and Differentiation, Vol. 15, No. 4, 2008, pp. 660-666. doi:10.1038/sj.cdd.4402307

[142] A. Heerschap, J. A. den Hollander, H. Reynen and R. J. Goris, "Metabolic Changes in Reflex Sympathetic Dystrophy: A 31P NMR Spectroscopy Study,” Muscle Nerve, Vol. 16, No. 4, 1993, pp. 367-373. doi:10.1002/mus.880160405

[143] T. L. Clanton, "Hypoxia-Induced Reactive Oxygen Species Formation in Skeletal Muscle," Journal of Applied Physiology, Vol. 102, No. 6, 2007, pp. 2379-2388. doi:10.1152/japplphysiol.01298.2006

[144] E. C. Tan, H. J. Ter Laak, M. T. Hopman, H. van Goor and R. J. Goris, "Impaired Oxygen Utilization in Skeletal Muscle of CRPS I Patients,” Journal of Surgical Research, Vol. 173, No. 1, 2012, pp. 145-152. doi:10.1016/j.jss.2010.08.043

[145] E. C. Tan, A. J. Janssen, P. Roestenberg, L. P. van den Heuvel, R. J. Goris and R. J. Rodenburg, "Mitochondrial Dysfunction in Muscle Tissue of Complex Regional Pain Syndrome Type I Patients,” European Journal of Pain, Vol. 15, No. 7, 2011, pp. 708-715. doi:10.1016/j.ejpain.2010.12.003

[146] K. B. Choksi, W. H. Boylston, J. P. Rabek, W. R. Widger and J. Papaconstantinou, "Oxidatively Damaged Proteins of Heart Mitochondrial Electron Transport Complexes," Biochimica et Biophysica Acta, Vol. 1688, No. 2, 2004, pp. 95-101. doi:10.1016/j.bbadis.2003.11.007

[147] E. Eisenberg, S. Shtahl, R. Geller, A. Z. Reznick, O. 
Sharf, M. Ravbinovich, et al., "Serum and Salivary Oxidative Analysis in Complex Regional Pain Syndrome," Pain, Vol. 138, No. 1, 2008, pp. 226-232. doi:10.1016/j.pain.2008.04.019

[148] R. S. Perez, W. W. Zuurmond, P. D. Bezemer, D. J. Kuik, Van A. C. Loenen, J. J. de Lange, et al., "The Treatment of Complex Regional Pain Syndrome Type I with Free Radical Scavengers: A Randomized Controlled Study,” Pain, Vol. 102, No. 3, 2003, pp. 297-307.

[149] L. van der Laan, H. J. ter Laak, A. Gabreels-Festen, F. Gabreels and R. J. Goris, "Complex Regional Pain Syndrome Type I (RSD): Pathology of Skeletal Muscle and Peripheral Nerve,” Neurology, Vol. 51, No. 1, 1998, pp. 20-25.

[150] T. Higashimoto, E. E. Baldwin, J. I. Gold and R. G. Boles, "Reflex Sympathetic Dystrophy: Complex Regional Pain Syndrome Type I in Children with Mitochondrial Disease and Maternal Inheritance," Archives of Disease in Childhood, Vol. 93, No. 5, 2008, pp. 390-397. doi:10.1136/adc.2007.123661

[151] F. Kozin, H. K. Genant, C. Bekerman and D. J. McCarty, "The Reflex Sympathetic Dystrophy Syndrome. II. Roentgenographic and Scintigraphic Evidence of Bilaterality and of Periarticular Accentuation," American Journal of Medicine, Vol. 60, No. 3, 1976, pp. 332-338.

[152] W. S. Kingery, S. C. Offley, T. Z. Guo, M. F. Davies, J. D. Clark and C. R. Jacobs, "A Substance P Receptor (NK1) Antagonist Enhances the Widespread Osteoporotic Effects of Sciatic Nerve Section,” Bone, Vol. 33, No. 6, 2003, pp. 927-936.

[153] M. E. Schweitzer, S. Mandel, R. J. Schwartzman, R. L. Knobler and A. J. Tahmoush, "Reflex Sympathetic Dystrophy Revisited: MR Imaging Findings before and after Infusion of Contrast Material,” Radiology, Vol. 195, No. 1, 1995, pp. 211-214.

[154] M. Hukkanen, Y. T. Konttinen, S. Santavirta, P. Paavolainen, X. H. Gu, G. Terenghi, et al., "Rapid Proliferation of Calcitonin Gene-Related Peptide-Immunoreactive Nerves during Healing of Rat Tibial Fracture Suggests Neural Involvement in Bone Growth and Remodelling,” Neuroscience, Vol. 54, No. 4, 1993, pp. 969-979.

[155] S. C. Offley, T. Z. Guo, T. Wei, J. D. Clark, H. Vogel, D. P. Lindsey, et al., "Capsaicin-Sensitive Sensory Neurons Contribute to the Maintenance of Trabecular Bone Integrity," Journal of Bone and Mineral Research, Vol. 20, No. 2, 2005, pp. 257-267. doi:10.1359/JBMR.041108

[156] S. Santavirta, Y. T. Konttinen, D. Nordstrom, A. Makela, T. Sorsa, M. Hukkanen, et al., "Immunologic Studies of Nonunited Fractures,” Acta Orthopaedica Scandinavica, Vol. 63, No. 6, 1992, pp. 579-586.

[157] M. E. Fundytus, K. Yashpal, J. G. Chabot, M. G. Osborne, C. D. Lefebvre, A. Dray, et al., "Knockdown of Spinal Metabotropic Glutamate Receptor 1 (mGluR(1)) Alleviates Pain and Restores Opioid Efficacy after Nerve Injury in Rats," British Journal of Pharmacology, Vol. 132, No. 1, 2001, pp. 354-367. doi:10.1038/sj.bjp.0703810

[158] R. Schwartzman and P. Ambady, "Tertiary Adrenal Insufficiency in CRPS: Effects of Chronic Pain on the Hypothalamic-Pituitary-Adrenal Axis,” Unpublished.
[159] M. Shibata, T. Ohkubo, H. Takahashi and R. Inoki, "Modified Formalin Test: Characteristic Biphasic Pain Response,” Pain, Vol. 38, No. 3, 1989, pp. 347-352.

[160] H. Logan, S. Lutgendorf, P. Rainville, D. Sheffield, K. Iverson and D. Lubaroff, "Effects of Stress and Relaxation on Capsaicin-Induced Pain,” Journal of Pain, Vol. 2, No. 3, 2001, pp. 160-170. doi:10.1054/jpai.2001.21597

[161] A. Tjolsen, O. G. Berge, S. Hunskaar, J. H. Rosland, K. Hole, "The Formalin Test: An Evaluation of the Method," Pain, Vol. 51, No. 1, 1992, pp. 5-17.

[162] W. Xie, X. Liu, H. Xuan, S. Luo, X. Zhao, Z. Zhou, et al., "Effect of Betamethasone on Neuropathic Pain and Cerebral Expression of NF-Kappab and Cytokines," Neuroscience Letters, Vol. 393, No. 2-3, 2006, pp. 255-259. doi:10.1016/j.neulet.2005.09.077

[163] J. D. Croxtall, Q. Choudhury and R. J. Flower, "Glucocorticoids Act within Minutes to Inhibit Recruitment of Signalling Factors to Activated EGF Receptors through a Receptor-Dependent, Transcription-Independent Mechanism,” British Journal of Pharmacology, Vol. 130, No. 2, 2000, pp. 289-298. doi:10.1038/sj.bjp.0703272

[164] M. Devor, R. Govrin-Lippmann and P. Raber, “Corticosteroids Suppress Ectopic Neural Discharge Originating in Experimental Neuromas,” Pain, Vol. 22, No. 2, 1985, pp. 127-137.

[165] A. Johansson, J. Hao and B. Sjolund, "Local Corticosteroid Application Blocks Transmission in Normal Nociceptive C-Fibres," Acta Orthopaedica Scandinavica, Vol. 34, No. 5, 1990, pp. 335-338.

[166] M. Qin, J. J. Wang, R. Cao, H. Zhang, L. Duan, B. Gao, et al., "The Lumbar Spinal Cord Glial Cells Actively Modulate Subcutaneous Formalin Induced Hyperalgesia in the Rat,” Neuroscience Research, Vol. 55, No. 4, 2006, pp. 442-450. doi:10.1016/j.neures.2006.04.017

[167] S. Hisano, S. Li, Y. Kagotani and S. Daikoku, "Synaptic Associations between Oxytocin-Containing Magnocellular Neurons and Neurons Containing Corticotropin-Releasing Factor in the Rat Magnocellular Paraventricular Nucleus,” Brain Research, Vol. 576, No. 2, 1992, pp. 311-318.

[168] M. C. Levin and P. E. Sawchenko, "Neuropeptide CoExpression in the Magnocellular Neurosecretory System of the Female Rat: Evidence for Differential Modulation by Estrogen," Neuroscience, Vol. 54, No. 4, 1993, pp. 1001-1018.

[169] A. Rhodin, M. Stridsberg and T. Gordh, “Opioid Endocrinopathy: A Clinical Problem in Patients with Chronic Pain and Long-Term Oral Opioid Treatment," Clinical Journal of Pain, Vol. 26, No. 5, 2010, pp. 374-380. doi:10.1097/AJP.0b013e3181d1059d

[170] G. F. Webster, R. V. Iozzo, R. J. Schwartzman, A. J. Tahmoush, R. L. Knobler and R. A. Jacoby, "Reflex Sympathetic Dystrophy: Occurrence of Chronic Edema and Nonimmune Bullous Skin Lesions," Journal of the American Academy of Dermatology, Vol. 28, No. 1, 1993, pp. 29-32.

[171] M. Milea, H. A. Dimov and B. Cribier, "Generalized Schamberg's Disease Treated with PUVA in a Child," 
Annales de Dermatologie et de Venereologie, Vol. 134, No. 4, 2007, pp. 378-380.

[172] J. E. Bernstein, M. Medenica, K. Soltani and S. F. Griem, "Bullous Eruption of Diabetes Mellitus," Archives of Dermatology, Vol. 115, No. 3, 1979, pp. 324-325.

[173] J. Toonstra, "Bullosis Diabeticorum. Report of a Case with a Review of the Literature," Journal of the American Academy of Dermatology, Vol. 13, No. 5, 1985, pp. 799805.

[174] A. Kurwa, P. Roberts and R. Whitehead, "Concurrence of Bullous and Atrophic Skin Lesions in Diabetes Mellitus," Archives of Dermatology, Vol. 103, No. 6, 1971, pp. 670675.

[175] P. J. Albrecht, S. Hines, E. Eisenberg, D. Pud, D. R. Finlay, M. K. Connolly, et al., "Pathologic Alterations of Cutaneous Innervation and Vasculature in Affected Limbs from Patients with Complex Regional Pain Syndrome,” Pain, Vol. 120, No. 3, 2006, pp. 244-266. doi:10.1016/j.pain.2005.10.035

[176] A. L. Oaklander, J. G. Rissmiller, L. B. Gelman, L. Zheng, Y. Chang and R. Gott, "Evidence of Focal SmallFiber Axonal Degeneration in Complex Regional Pain Syndrome-I (Reflex Sympathetic Dystrophy),” Pain, Vol. 120, No. 3, 2006, pp. 235-243. doi:10.1016/j.pain.2005.09.036

[177] S. Kharkar, Y. Venkatesh, J. Grothusen, L. Rojas and R. J. Schwartzman, "Skin Biopsy in Chronic Regional Pain Syndrome: Case Series and Literature Review," Pain Physician, Vol. 15, No. 3, 2012, pp. 255-266.

[178] P. D. Drummond, P. M. Finch and I. Gibbins, "Innervation of Hyperalgesic Skin in Patients with Complex Regional Pain Syndrome,” Clinical Journal of Pain, Vol. 12, No. 3, 1996, pp. 222-231.

[179] S. T. Hsieh and W. M. Lin, "Modulation of Keratinocyte Proliferation by Skin Innervation," Journal of Investigative Dermatology, Vol. 113, No. 4, 1999, pp. 579-586. doi:10.1046/j.1523-1747.1999.00737.x

[180] C. A. Maggi, F. Borsini, P. Santicioli, P. Geppetti, L. Abelli, S. Evangelista, et al., "Cutaneous Lesions in Capsaicin-Pretreated Rats. A Trophic Role of CapsaicinSensitive Afferents?” Naunyn Schmiedebergs Arch Pharmacology, Vol. 336, No. 5, 1987, pp. 538-545.

[181] P. Sandroni, P. A. Low, T. Ferrer, T. L. Opfer-Gehrking, C. L. Willner and P. R. Wilson, "Complex Regional Pain Syndrome I (CRPS I): Prospective Study and Laboratory Evaluation,” Clinical Journal of Pain, Vol. 14, No. 4, 1998, pp. 282-289.

[182] F. H. Gardner and L. K. Diamond, “Autoerythrocyte Sensitization; a Form of Purpura Producing Painful Bruising Following Autosensitization to Red Blood Cells in Certain Women,” Blood, Vol. 10, No. 7, 1955, pp. 675-690.

[183] O. L. Ivanov, A. N. Lvov, A. V. Michenko, J. Kunzel, P. Mayser and U. Gieler, "Autoerythrocyte Sensitization Syndrome (Gardner-Diamond Syndrome): Review of the Literature," Journal of the European Academy of Dermatology and Venereology, Vol. 23, No. 5, 2009, pp. 499504. doi:10.1111/j.1468-3083.2009.03096.x

[184] D. Cansu, T. Kasifoglu, O. Pasaoglu and C. Korkmaz, “Autoerythrocyte Sensitization Syndrome (Gardner-Dia- mond Syndrome) Associated with Cutaneous Vasculitis," Joint Bone Spine, Vol. 75, No. 6, 2008, pp. 721-724. doi:10.1016/j.jbspin.2007.10.007

[185] A. Strunecka, L. Krpejsova, J. Palecek, J. Macha, M. Maturova, L. Rosa, et al., "Transbilayer Redistribution of Phosphatidylserine in Erythrocytes of a Patient with Autoerythrocyte Sensitization Syndrome (Psychogenic purpura)," Folia Haematol Int Mag Klin Morphol Blutforsch, Vol. 117, No. 6, 1990, pp. 829-841.

[186] F. Birklein, “Complex Regional Pain Syndrome,” Journal of Neurology, Vol. 252, No. 2, 2005, pp. 131-138. doi:10.1007/s00415-005-0737-8

[187] J. Marinus, G. L. Moseley, F. Birklein, R. Baron, C. Maihofner, W. S. Kingery, et al., "Clinical Features and Pathophysiology of Complex Regional Pain Syndrome," Lancet Neurology, Vol. 10, No. 7, 2011, pp. 637-648. doi:10.1016/S1474-4422(11)70106-5

[188] M. B. Chancellor, P. J. Shenot, D. A. Rivas, S. Mandel and R. J. Schwartzman, "Urological Symptomatology in Patients with Reflex Sympathetic Dystrophy,” Journal of Urology, Vol. 155, No. 2, 1996, pp. 634-637.

[189] J. E. Chalkley, C. Lander and J. C. Rowlingson, "Probable Reflex Sympathetic Dystrophy of the Penis," Pain, Vol. 25, No. 2, 1986, pp. 223-225.

[190] W. L. Olson, "Perineal Reflex Sympathetic Dystrophy Treated with Bilateral Lumbar Sympathectomy,” Annals of Internal Medicine, Vol. 113, No. 8, 1990, pp. 633-634.

[191] D. J. Libon, M. W. Bondi, C. C. Price, M. Lamar, J. Eppig, D. M. Wambach, et al., "Verbal Serial List Learning in Mild Cognitive Impairment: A Profile Analysis of Interference, Forgetting, and Errors," Journal of the International Neuropsychological Society: JINS, Vol. 17, No. 5, 2011, pp. 905-914. doi:10.1017/S1355617711000944

[192] M. B. Yunus, "The Prevalence of Fibromyalgia in Other Chronic Pain Conditions," Pain Research and Treatment, Vol. 2012, No. 2012, Article ID: 584573. doi:10.1155/2012/584573

[193] B. L. Loevinger, D. Muller, C. Alonso and C. L. Coe, "Metabolic Syndrome in Women with Chronic Pain," Metabolism, Vol. 56, No. 1, 2007, pp. 87-93. doi:10.1016/j.metabol.2006.09.001

[194] S. C. T. Safder, E. Heller and G. Chelimsky, "Non-Psychiatric Co-Morbidities in Pediatric Functional Gastrointestinal Disorder (FGID): An Area in Need of Exploration,” Clinical Autonomic Research, Vol. 18, No. 5, 2008, pp. 241-287.

[195] G. Chelimsky, S. Madan, A. Alshekhlee, E. Heller, K. McNeeley and T. Chelimsky, "A Comparison of Dysautonomias Comorbid with Cyclic Vomiting Syndrome and with Migraine," Gastroenterology Research and Practice, Vol. 2009, No. 2009, Article ID: 701019. doi:10.1155/2009/701019

[196] C. Quattrini, M. Jeziorska and R. A. Malik, "Small Fiber Neuropathy in Diabetes: Clinical Consequence and Assessment," The International Journal of Lower Extremity Wounds, Vol. 3, No. 1, 2004, pp. 16-21. doi:10.1177/1534734603262483

[197] S. E. Lakhan and A. Kirchgessner, "Gut Inflammation in Chronic Fatigue Syndrome,” Nutrition \& Metabolism, 
Vol. 7, 2010, p. 79. doi:10.1186/1743-7075-7-79

[198] M. Costigan, J. Scholz and C. J. Woolf, "Neuropathic Pain: A Maladaptive Response of the Nervous System to
Damage," Annual Review of Neuroscience, Vol. 32, No. 2009, pp. 1-32.

doi:10.1146/annurev.neuro.051508.135531
Complex Regional Pain Syndrome (CRPS)

intercostobrachial (ICB)

Wechsler Adult Intelligence Scale-III (WAIS-III)

functional MRI (fMRI)

primary somatosensory cortex (SI)

secondary somatosensory cortices (SII)

blood brain barrier (BBB)

tumor necrosis factor-alpha (TNF- $\alpha$ )

nuclear factor kappa B (NF- $\kappa \mathrm{B})$

$\mathrm{nAChR}$ (acetylcholine receptor)

interleukin-6 (IL-6)

interleukin-10 (IL-10)

interleukin-1 (IL-1)

head-up tilt test (HUTT)

coronary artery disease (CAD)

Gastroesophageal reflux disease (GERD)

second intercostal nerve (T2)

chronic obstructive lung disease (COPD)

dorsal root ganglion (DRG)

lymphocyte inhibitory factor (LIF)

prostaglandins (PGE2)

\section{Abbreviation List}

neurotrophic factors (nerve growth factor (NGF)

brain derived neurotrophic factor (BDNF)

neurotrophin-3 (NT-3)

phosphokinase A (PKA)

phosphokinase C (PKC)

tetrodotoxin (TTX)

interleukin-1 beta (IL-1 $\beta$ )

calcitonin gene related peptide (CGRP)

interleukin-8 (IL-8)

transforming growth factor beta-1 (TGF $\beta$-1)

N-Methyl-D-aspartate (NMDA)

hypoxia inducible factors (HIPs)

reactive oxygen species (ROS)

adrenocorticotrophic hormone (ACTH)

arteriovenous shunt (AVS)

central sensitization syndrome (CSS)

irritable bowel syndrome (IBS)

fibromyalgia (FB)

cyclic vomiting syndrome (CVS)

gastrointestinal (GI) 